\title{
Capture the variation of acoustic impedance property in the Jaisalmer Formation due to structural deformation based on post-stack seismic inversion study: a case study from Jaisalmer sub-basin, India
}

\author{
Saurabh Datta Gupta ${ }^{1} \cdot$ Sugata Kumar Sinha ${ }^{1} \cdot$ Raman Chahal $^{1}$
}

Received: 27 July 2021 / Accepted: 22 December 2021 / Published online: 4 January 2022

(C) The Author(s) 2022

\begin{abstract}
The Rajasthan basin situates in the western part of India. The basin architecture comprises three significant sub-basins such as Barmer-Sanchor, Bikaner-Nagaur and Jaisalmer. Barmer-Sanchor and Bikaner-Nagaur sub-basins are intracratonic categories, whereas the Jaisalmer sub-basin comes under intracratonic nature. The current study was conducted in the Jaisalmer subbasin. The study was conducted in two regions in the Jaisalmer sub-basin through a comparative quantitative interpretation study with the help of two vintages seismic surveys. Ghotaru and Bandha are two adjacent areas in the Jaisalmer sub-basin where Ghotaru has seen few hydrocarbon discoveries; however, no such discoveries are encountered in the Bandha area. The current study was concentrated on the Jaisalmer limestone formation in the Jurassic age. The sub-basin and its related study area have been structurally deformed due to various tectonic activities. Structural deformation was played a crucial role in changing the rock property of limestone facies. A post-stack seismic inversion was carried out to capture the rock property changes in the limestone reservoir based on P-impedance values. Development of high P-impedance was observed in the Ghotaru region compared to the Bandha region from this study. A frequency changes of the limestone lithofacies with structural components was also captured in this study. The high impedance limestone lithofacies is a probable hydrocarbonbearing reservoir unit in the Jaisalmer Formation of the Ghotaru region.
\end{abstract}

Keywords Jaisalmer sub-basin, India $\cdot$ Structural heterogeneity $\cdot$ Post-stack Inversion · Acoustic Impedance Limestone lithofacies $\cdot$ Hydrocarbon exploration

\section{Introduction}

Jaisalmer sub-basin is a part of the Rajasthan basin where several signatures of the tectonic activities in the form of faults are observed. Several significant faults are observed in the basement of the Precambrian age, which are extended up to the Pariwar Formation of Cretaceous age. Jaisalmer Formation of the Jurassic age was similarly affected by different

Saurabh Datta Gupta

sdattagupta237@gmail.com

Sugata Kumar Sinha

sugatasinha1990@gmail.com

Raman Chahal

ramanchahal75@gmail.com

1 Department of Applied Geophysics, Indian Institute of Technology (Indian School of Mines), Dhanbad PIN-826004, Jharkhand, India tectonic activities, where the presence of the small and high aperture faulting system verifies its authenticity. The study focused on the Jaisalmer Formation of the Ghotaru and Bandha (Fig. 1) region in the Jaisalmer sub-basin, where this kind of tectonic deformation has also been observed. Post depositional tectonic activities change the rock properties due to different geo-mechanical setups. It shows significant differences in the compressional velocity and density of the rock property between pre and post tectonic activities, representing the changes of AI properties in both instances. Few hydrocarbon discoveries had been made from the Lower Goru Formation in the Lower Cretaceous age. However, any success did not report from the Jaisalmer Formation. The current study was conducted in the Jaisalmer limestone formation to capture the acoustic impedance (AI) property variations from Ghotaru to the Bandha region. The Jaisalmer Formation is a comparatively deeper formation than the established hydrocarbon-bearing formation of the Jurassic age. The distribution of hydrocarbon-bearing reservoir 


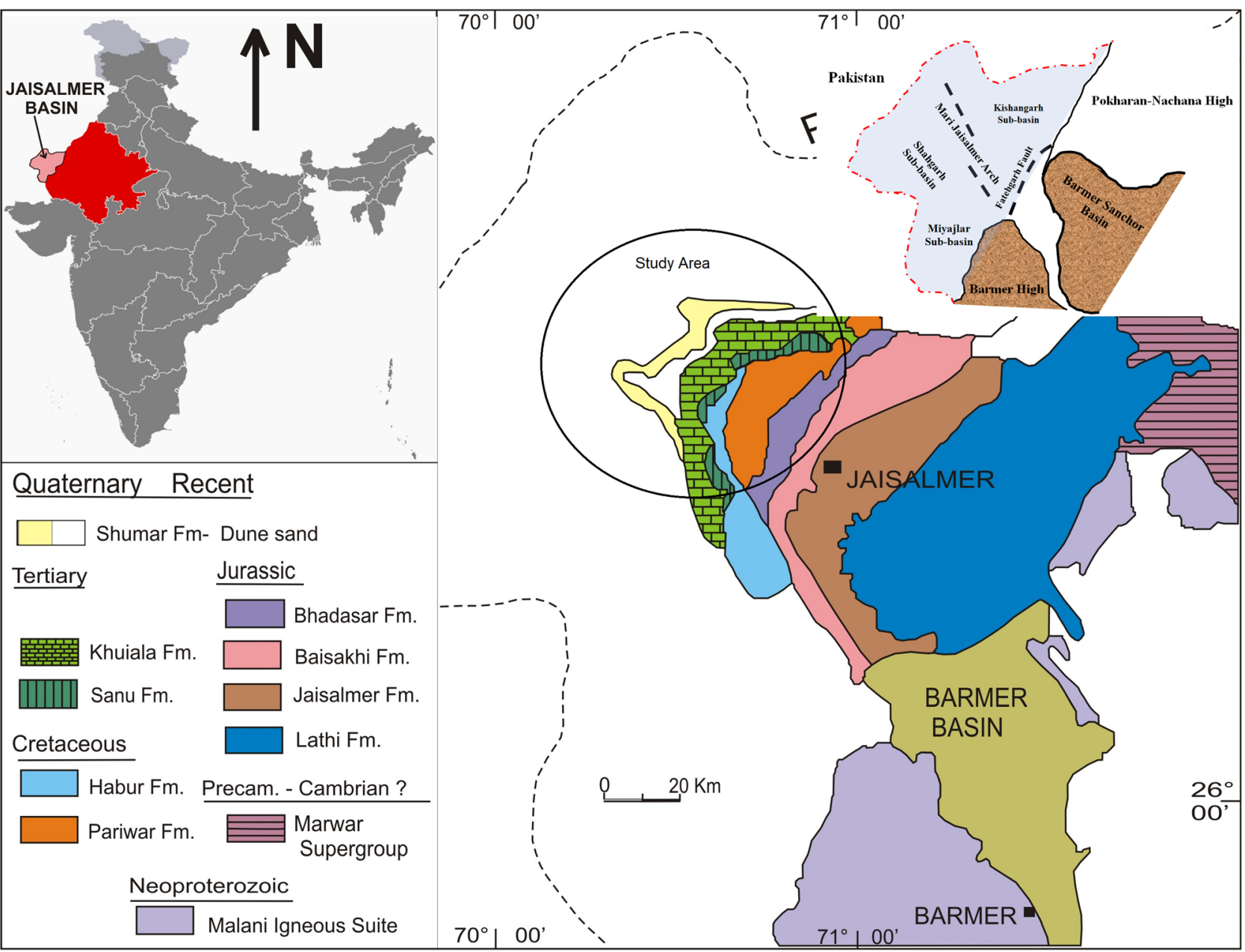

Fig. 1 Representation of structural deformation and hetroginity of sediment deposition in the formations of the Jaisalmer sub-basin (modified after Srivastave and Ranawat 2015; Jain and Garg, 2012)

lithofacies has been identified based on this comparison study, where changes in the AI property have been identified. The study area is surrounded by multiple high gravity structures, many of which are oil and gas fields (Desai and Saklani 2014): Bakhri Tibba, Vikhran Nai, Manhera Tibba, and Ghotaru ( DGH 2007).

Seismic inversion is a part of the quantitative interpretation (QI), which is adopted to build the properties of the sedimentary layers in the sub-surface geology. The study produces impedance property of the rock through the integration of seismic, well log and its related geoscientific data. Seismic inversion plays a crucial role in reservoir characterization, such as lithofacies identification and fluid characterization. The uses of the seismic inversion output are significant for the position away from the well. This output is used to estimate the petrophysical properties of the hydrocarbon-bearing reservoir, such as porosity, water saturation, and permeability. The successful exploration of oil and gas from the Jaisalmer limestone formation is challenging due to limited, encouraging facies with encouraging petrophysical properties and frequent changes of the reservoir lithofacies. Here, we have been used two vintages of the post-stack seismic data for analysis purposes. Both the vintages are 3D seismic data, and the coverage of the seismic data used for this study in both vintages are 50 Sq.km and 676 Sq.km. Pre-stack seismic data are available in the Bandha region, but data quality is not adequate to carry out pre-stack inversion, whereas, in the Ghotaru region, pre-stack seismic data is not available. Ghotaru field was discovered in the 1980s, where advanced well data also not available. However, based on conventional well log data from six well data (two from Ghotaru and four from the Bandha region), this study was conducted. Several studies show the maturity of the petroleum system in the study area (DGH 2007), where the Jaisalmer limestone formation has been considered a potential reservoir with source rock (Pandey and Maurya 2020). Limited explorations have been carried out in the Jaisalmer Formation, and hydrocarbon discoveries did not report. 
Although lithofacies, biofacies, and depositional facies in this formation have been reported (Pandey and Maurya 2020). However, the presence of suitable conditions for hydrocarbon exploration lot of challenges is involved. The Jaisalmer Formation in the Bandha region has a low potential hydrocarbon in comparison to the Jaisalmer Ghotaru region (Mishra and Sharma 1986). There are limited numbers of studies that have been carried out in the Jaisalmer Formation where integrated approaches of both seismic and well $\log$ have been adopted. The significance of the structural heterogeneity towards changes of the reservoir properties such as acoustic and geo-mechanical in the Bandha region has been represented through integrated QI analysis (Chahal and Datta Gupta 2020). It is highly significant to analyze the variation of the rock properties in terms of acoustic and fluid in the reservoir lithofacies in both the Bandha and Ghotaru region using the acoustic impedance to know the effect of structural heterogeneity in this area. A model-based P-wave post-stack seismic inversion process has been conducted in this research (Bateman 1985). The acoustic impedance obtained from the well log data helps to capture changes in the rock properties in a detailed manner in both areas. The changes aways from the well have been integrated based on the inversion study. Initially, a robust structural model of the Jaisalmer Formation has been prepared, extending up to the top of the Lathi Formation. The model has been prepared based on the structural interpretation of the formation. A robust approach on well to seismic tie with a high cross-correlation coefficient provides significant support to develop a structural model. This process provides multiple wavelets from six well data; the variations of these wavelets are optimized during the adoption of the seismic inversion process. The integrated time-depth relationship between well and seismic data provides a calibrated picture of the seismic signature in the sub-surface geology. Robust calibration of the velocity function in both areas shows a comprehensive comparison of structural changes. P-wave impedance from the post-stack seismic inversion from the Bandha to Ghotaru region in the Jaisalmer Formation provides a notable outcome on rock property changes in this area. Kanoi, Ghotaru and Ramgarh's faults are involved significantly in developing a matured rock property for hydrocarbon exploration in this study area. The changes of the hydrocarbon-bearing carbonate reservoir facies have been captured along this faulted structure. In a similar regional geological setup, subtle changes of acoustic impedance (AI) property of the limestone reservoir due to structural deformation has been identified in two areas such as Ghotaru and Bandha. Two areas are $50 \mathrm{~km}$ apart based on surface distance.

The current study shows higher challenges in the Bandha region compared to the Ghotaru region for hydrocarbon exploration from the Jaisalmer Formation (Pandey et al. 2019).
However, advanced study with modern technology can be a significant success in the Jaisalmer Formation for hydrocarbon exploration, which was not reported in this region.

Compared to the Ghotaru region, the acoustic impedance (AI) property has changed drastically for the Bandha region. The potentiality hydrocarbon-bearing reservoir lithofacies in the carbonate facies of the Jaisalmer Formation has been established in this study. The comparison study based on the acoustic impedance (AI) property variation for the Jaisalmer Formation is unique for this study area.

\section{Geology of the study area}

The Jaisalmer sub-basin is a part of the Rajasthan basin which extends from the west and northwest part of the Aravalli's range to the Indo-Pakistan border (Biswas 1987) (Report published in Director General of Hydrocarbon (DGH) 2007); situates in the north-western slope of the peninsular shield of India. Evidence shows the western shelf in the Rajasthan basin is a segment of the Indus basin, and it was developed during the Precambrian age (Henderson et al. 2010; Inam et al. 2007). Significant tectonic activities are captured in the structural history of the basin during Proterozoic to Lower Cambrian (Singh 2006) (Report published in Director General of Hydrocarbon (DGH) 2007) in the form of upliftment and hiatus. We have found a major event on regression during Triassic and Early Jurassic in this basin (Singh et al. 2006). A crucial evolutionary process in the sedimentary basin took place in the Barmer, Jaisalmer and Bikaner region during the Cretaceous to Tertiary age. Intracratonic rift basin developed under extensional tectonic activities from the early Jurassic to tertiary time (Pandey et al. 2012). As the result of the rift evolution, there was alkaline magnetism at the rift margin (Arora et al. 2012). The Rajasthan basin is one of the oldest sedimentary basins in India and has more than $5000 \mathrm{~m}$ sediment thickness. The faulted structure and cratonic sequences (pre and intra) have made classifications of the sediments. The Rajasthan basin has been divided into three sub-basinal parts: (1) Jaisalmer sub-basin, (2) Bikaner-Nagaur sub-basin and (3) BarmerSanchor sub-basin (Fig. 1). The current study has been carried out in the Jaisalmer sub-basin, which is filled with pre-cratonic sediments. Structurally the Jaisalmer subbasin shows two different depression and shelf such as Shahgarh, Miajlar and Kishangarh (Report published in Director General of Hydrocarbon (DGH), 2007); Singh 2006). One significant arch has been identified in this subbasin, known as the Mari-Jaisalmer arch (Dasgupta 1974). The sub-basin is dipping towards the northwest direction. This arch is situated in the central part of this sub-basin 
and separates the Kishangarh and Shahgarh depression in the north and south. Our study area comes under Shahgarh depression and Kishangarh shelf of Jaisalmer sub-basin (Fig. 1).

The outcrop of the sub-basin shows the prominent signature of the sediments in the non-marine and shallow marine condition; sediments are siliciclastic to marine carbonate. The older sediments that were deposited during the Mesozoic period are non-marine, and the nature of the deposition is fluvial, deltaic or lacustrine (Dasgupta 1975). However, in the latter time presence of marine sediments have been observed in this sub-basin. Changes in the sea level show the high degree of variations in the deposition of the sediments in the chrono-stratigraphy column in this sub-basin. The nature of the deposits are non-marine, marginal marine, then again non-marine, marginal marine and fully marine. It shows that exploration activity in this sub-basin is challenging. The succession of the Jaisalmer sub-basin represents the deposition of shale, siltstone and limestone during the Mesozoic period (Krishna 1987). The name of the few major sedimentary units identified from the analysis of lithostratigraphy is Randha, Birmania, Bhuana, Lathi, Jaisalmer, Baisakhi-Bedesir, Pariwar, Goru, Sanu and Khuiala formations. The basement of this sub-basin belongs to the Precambrian age comprised of igneous or metamorphic rock.

Several studies in this sub-basin have been shown the maturity of the petroleum system in this sub-basin which shows the possibilities for hydrocarbon exploration (Pandey et al. 2019; Wandrey et al. 2004; Pandey and Maurya 2020; Srivastava et. al. 1995). The Baisakhi-Bedesir, Pariwar, Goru, Sanu, and Khuiala Formations are examples of clastic reservoir, whereas fractured limestones of the Jaisalmer Formation and limestone of the Lower Bandah/Khuiala Formation are considered as carbonate reservoir (Biswas 1987) (Report published in Director General of Hydrocarbon (DGH), 2007). Different organic material rich shale formations are considered as source rock such as Lower Goru,
Pariwar, Sembar/Bedesir-Baisakhi shales, Karampur/Badhaura shales, Bilara Shales, and the Dolomites with algal rich layers (Wandrey et al. 2004; Upadhyay 1991).

Our current study has been focused on the sediments of the Jurassic age, which extends from Lathi to BaisakhiBedesir Formation, where a significant part is the Jaisalmer Formation. The overlying unit of the Lathi Formation is Jaisalmer, and the formations are dominated by limestone lithology. Other than limestone, shale, sandstone, and siltstone are the lithologies which are identified in this formation. The primary focus of the current study is in this Jaisalmer Formation, which has a thickness of 330-360 m (Gupta et al. 1996). The analysis was conducted based on the limited number of the dataset and data quality in the Ghotaru and Bandha region. The summary of the available well and seismic dataset has been mentioned in the Table 1.

The thickness of the formation has been increased to $600 \mathrm{~m}$ when it comes to the exposed condition in few areas of the sub-basin. Based on sediment depositional sequences, the Jaisalmer Formation has been divided into six members: Jajya, Kuldhar, Bada Bag, Fort, Joyan and Hamira Member. The current study areas such as Ghotaru and Bandha are affected by structural deformations, and the presence of major faults such as Ghotaru, Kanoi and Ramgarh faults are examples of such deformations (Fig. 2).

\section{Methodology}

Seismic inversion eliminates the impression of the wavelet in the seismic data through deconvolution and then modifies the output into impedance. The primary classification of the inversion process is pre-stack and post-stack seismic inversion. Deterministic and stochastic are another classification for the seismic inversion process based on the outcome. Few other inversion processes such as coloured and genetic are also used to delineate the reservoir properties by adopting

Table 1 Available log data for the six wells from the Jaisalmer basin

\begin{tabular}{|c|c|c|c|c|c|c|c|}
\hline Well name & SP & Gamma ray & Neutron porosity & P-wave & Density & Resistivity & Region \\
\hline W-S & $\sqrt{ }$ & $\sqrt{ }$ & $\sqrt{ }$ & $\sqrt{ }$ & $\sqrt{ }$ & $\sqrt{ }$ & Bandha \\
\hline W-D & $\sqrt{ }$ & $\sqrt{ }$ & $\sqrt{ }$ & $\sqrt{ }$ & $\sqrt{ }$ & $\sqrt{ }$ & Bandha \\
\hline W-3 & $\sqrt{ }$ & - & - & $\sqrt{ }$ & $\sqrt{ }$ & & Ghotaru \\
\hline W-4 & $\sqrt{ }$ & - & - & $\sqrt{ }$ & $\sqrt{ }$ & $\sqrt{ }$ & Ghotaru \\
\hline $\mathrm{W}-\mathrm{C}$ & $\sqrt{ }$ & $\sqrt{ }$ & $\sqrt{ }$ & $\sqrt{ }$ & $\sqrt{ }$ & $\sqrt{ }$ & Bandha \\
\hline W-B & $\sqrt{ }$ & $\sqrt{ }$ & $\sqrt{ }$ & $\sqrt{ }$ & $\sqrt{ }$ & $\sqrt{ }$ & Bandha \\
\hline \multirow[t]{2}{*}{ Seismic data } & & \multicolumn{4}{|c|}{ Pre-stack seismic } & \multirow{2}{*}{\multicolumn{2}{|c|}{ Post-stack seismic }} \\
\hline & & Near $\left(\right.$ in $\left.^{\circ}\right)$ & \multicolumn{2}{|l|}{$\operatorname{Mid}\left(\right.$ in $\left.^{\circ}\right)$} & Far $\left(\right.$ in $\left.^{\circ}\right)$ & & \\
\hline Bandha & & $10-15$ & \multicolumn{2}{|l|}{$15-30$} & $30-45$ & \multicolumn{2}{|c|}{$\sqrt{ }($ Vintage 1$)$} \\
\hline Ghotaru & & - & & & & \multicolumn{2}{|c|}{$\sqrt{ }$ (Vintage 2$)$} \\
\hline
\end{tabular}


Fig. 2 The study area of the Jaisalmer sub-basin comprises both Ghotaru and Bandha region; two vintages of the post-stack seismic survey and six well are used for this study; Bandha region consists of seismic survey vintage \#1, whereas for the Ghotaru region, it is seismic survey vintage \#2; an earlier discovery field situated near to the study area

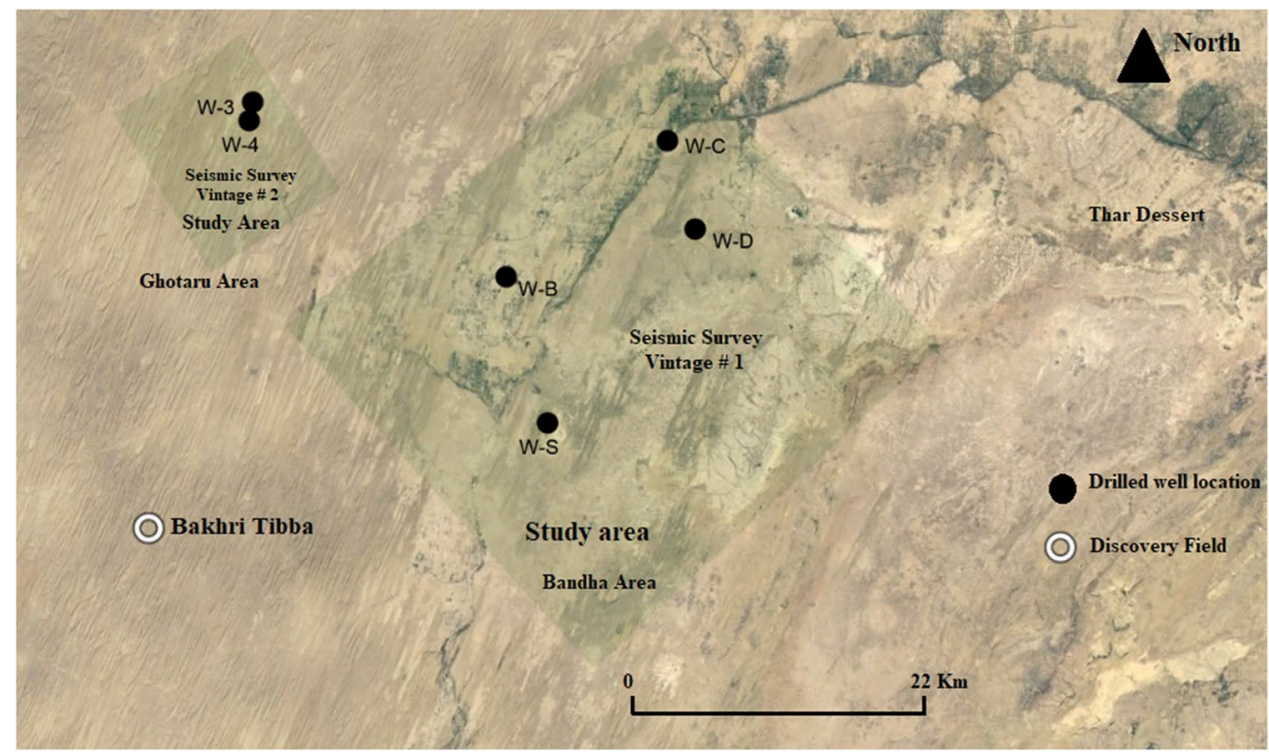

various algorithms. However, any inversion process largely depends upon the data quality and its feasibility with reservoir rock property. The post-stack seismic inversion method modifies a migrated zero offset full-stack seismic volume into an acoustic impedance volume by using seismic and wells data along with the essential information of structure and stratigraphy for interpretation. The pre-stack seismic data such as angle stack and offset gathers are used for the pre-stack inversion process, which produces P-impedance, S-impedance and density of rock properties primarily. Poststack inversion methods refer to various sequences used to convert stacked seismic data into measurable rock physics parameters (Mangasi and Haris 2018; Weber 1987). In this inversion, the result is P-impedance. In the inversion process, all frequency components such as ultra-low, low, bandlimited and high frequency are used where ultra-lowand low-frequency component is incorporated from seismic velocity and well data. High frequencies are added by well data, whereas the band-limited frequency added by seismic data (Berge et al. 2002). A considerable correlation was achieved between well to seismic tie. The analysis shows the variation of the acoustic impedance property of the rock. Suitable frequency and time filters were applied on the wavelets towards conditioning during well to seismic tie, which provides a robust analysis. The goal of the study has been achieved based on the analysis of post-stack seismic inversion.

\section{Seismic data analysis}

The quality of the post-stack seismic data shows a good representation based on amplitude and frequency distribution. The bandwidth of the seismic data in the Bandha region varies from 10 to $70 \mathrm{~Hz}$, whereas in the Ghotaru region, it varies from 12 to $66 \mathrm{~Hz}$. The amplitude spectrum shows a uniform distribution without any skewness. However, in the data of the Bandha region, few acquisition footprints such as locality and noises in the angle stack data are observed. A preliminary pre-processing step such FK filter in FKX-KY was applied to remove these acquisition footprints. However, the adoption of the filtering process shows a degradation of the seismic dataset in the deeper section for both inline and cross-line direction. This application has shown the removal of the significant portion of the signal in the deeper where Jaisalmer Formation is placed. The situation suggests avoiding the application of the filtering process. In all angle stack (near, mid and far), seismic data of Bandha region the reflection continuity is visible in the Jaisalmer Formation only; however, quality for near angle stack data is insufficient for performing pre-stack inversion process whereas angle stack was not available in Ghotaru region.

\section{Petrophysical analysis}

The petrophysical evaluation was carried out for the Jaisalmer Formations encountered, which included the carbonate reservoirs primarily. Volumetric analysis was performed at the well level based on the numerical analysis, which represents the mineral components of the reservoir. Various petrophysical properties such as porosity, water saturation and volume of shale were estimated from the petrophysical analysis. Different input parameters such as clay typing, formation water salinity, and mineral model were considered to estimate the petrophysical components that are sensitive to the mineralogical components. The present petrophysical study has been conducted in the Jaisalmer Formation, which 
is a limestone dominate formation. The effect of the shaly sand is significant in this formation.

In view of the reservoir component, the Dual Water (Clavier et al. 1984) shaly sand analysis model was employed in this study. The model was built up based on the additional conductivity parameter to compensate for the deficiency of the electrical charges in the clay surrounded diffuse layer. Cementation factor (m) and saturation component (n) are the other two significant parameters for the Dual Water model. Both the factors depend upon the porosity of the rock, which is known as tortuosity. The tortuosity varies with grain size and type of clay. The formation water salinity was obtained based on the Pickett plot from the drilled wells. SP log was used for the generation of the picket plot. During the Dual Water saturation model estimation, $\mathrm{a}=1, \mathrm{~m}=2.0$ and $\mathrm{n}=2.0$ were assumed in the absence of core data. Note that the " $\mathrm{m}$ " parameter depends on rock texture which can vary considerably in carbonate over Jaisalmer Formation and that " $m$ " can be much higher than 2.0 in vuggy carbonates. Water saturation increases with an increase in $m$ and vice versa. The numerical estimation of the salinity in the Jaisalmer Formation comes around $100 \mathrm{ppK}$. Quartz, Calcite, Slate, Ferruginous mineral, Clay are the major mineral components that have been identified, whereas in the fluid component, hydrocarbon and water both are identified from the petrophysical analysis. The range of porosity shows $3 \%$ to $10 \%$ in the Jaisalmer Formation as the formation is considered tight.

\section{Structural interpretation}

Structural interpretation has been played a crucial role in this study. The most challenging task was structural interpretation around the two major faults in the study area due to the poor image quality of the seismic data. The poor image continues along strike direction-NNW to SSE of the Western fault in the study area due to the shear zone and the fault plane, which is the path of gas movement (Fig. 3a). In the Jaisalmer limestone formation only, a high impedance contrast in the seismic image has been observed. The high impedance contrast has also been observed in the intra-Jaisalmer marker, which separates the interested lithology from others. The unavailability of VSP or check shot data in most wells enhances the uncertainty in the structural interpretation of the study formation. A detailed well correlation between six study wells (Fig. 3b) has provided a comprehensive image of the structural setup of the Jaisalmer Formation. Well to Seismic tie process was performed in these six wells (Figs. 4, 5, 6, 7, 8, 9). The tie was performed between the Jaisalmer Formation. The extraction of the proper wavelets and establishing the time to depth relationship was the primary goal of the well to seismic tie. Check shot data were used as time-depth relation for two wells, whereas for the other wells P-sonic data were used for calibration. Identification of quantitative parameters of the reservoir based on amplitude, phase, frequency variation was another motto of the well to seismic tie. Fault interpretation is a significant part of the structural analysis. The coherency cube of the post-stack seismic data provided significant support to fault analysis in this area. A structural framework was developed through the positional changes of the formation marker to capture the extensive structural variability in the study area, which provided important information for interpreting sub-surface geology. The structural interpretation based on the post-stack seismic data from Ghotaru and Bandha regions shows sub-surface geological complexity. The TWT (two-way travel time) structural contour map in the Bandha and Ghotaru region represents possibilities of rock property changes due to frequent changes in the structural setup (Fig. 10 a, b).

An integrated approach was adopted to prepare a robust velocity model. The velocity model was used for building an ultra-low frequency model away from the well position. Well to seismic tie to structural interpretation, each step played a crucial role in building a robust velocity model (Pradhan et al. 2019). Robust estimation of the time-depth relationship and check shot (W-4) were used to calibrate the seismicbased average velocity cube generated from seismic stacking velocity. The subtle changes in limestone formation have also been captured in this integrated velocity model. Uncertainty analysis of the velocity model has been performed based on P10, P50 and P90 assessment where the variations of the compressional velocity have been observed between $4836 \mathrm{~m} / \mathrm{s}$ to $5618 \mathrm{~m} / \mathrm{s}$ considering all three cases (Fig. 11).

\section{Editing of well data and rock physics modelling}

Rock physics analysis is a significant part of the QI study where a robust relationship is established between petrophysical (Porosity, $\mathrm{V}_{\mathrm{cl}}$, Water saturation) and rock physical (acoustic impedance, bulk modulus, shear modulus) properties. In the QI study, information of well log data is essential for extracting various information such as wavelet extraction and low-frequency information. Seismic data provides bandlimited frequency, which shows the essentiality of well information. The information available based on quantitative well to seismic tie provides significant information to the rock physics modelling and its related seismic inversion process. The complete work was adopted based on the following workflow (Fig. 12).

Well log data provides information for elastic property inversion for seismic reflection where high-quality log data is required. Rock physics analysis provides that important high-resolution information for the inversion process.

Well $\log$ data are affected by various bad influences such as borehole rugosity, casing shoes and washout regions. These unwanted influences represent incorrect 
(a)
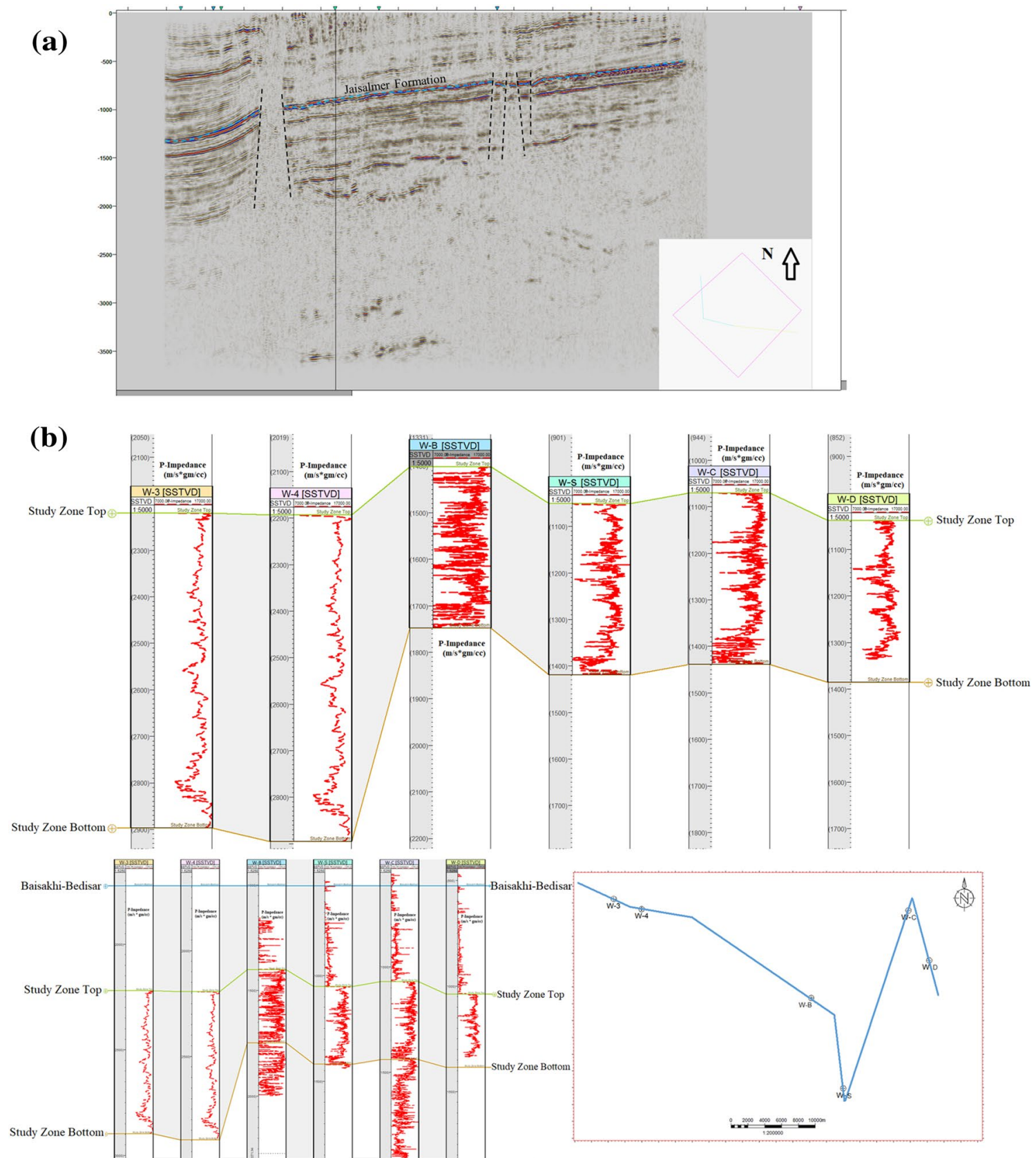

Fig. 3 a Distribution of seismic section from NNW to SSE to represents the structural setup of the study area (Bandha region). b Well correlation between the wells from the Ghotaru and Bandha region; W-3, W-4, W-B, W-S, W-C and W-D wells are used for this correla-

information through shallow readings. Sometimes well $\log$ data are influenced by instrument malfunction, such as cycle skipping in the sonic log, which shows the missing readings. Rock physics modelling depends upon the sonic and density log; hence quality control and editing of density, sonic and acoustic log were adopted in this study to prepare robust rock physics modelling. In few instances, numerical approaches were adopted where well tion; Jaisalmer Formation of the Ghotaru region is in the downthrown side of a throw between 800 and $1200 \mathrm{~m}$; P-impedance log has been used for this correlation

log data was not available based on synthetic well log data. The synthetic log data were prepared based on regression methods and established an empirical relationship between rock physics properties.

The well log data were conditioned and noise-free to maintain the sub-surface geological trend. The scattered cross plot between rock physics parameters helped identify the noisy data points. The noisy data points were mitigated 


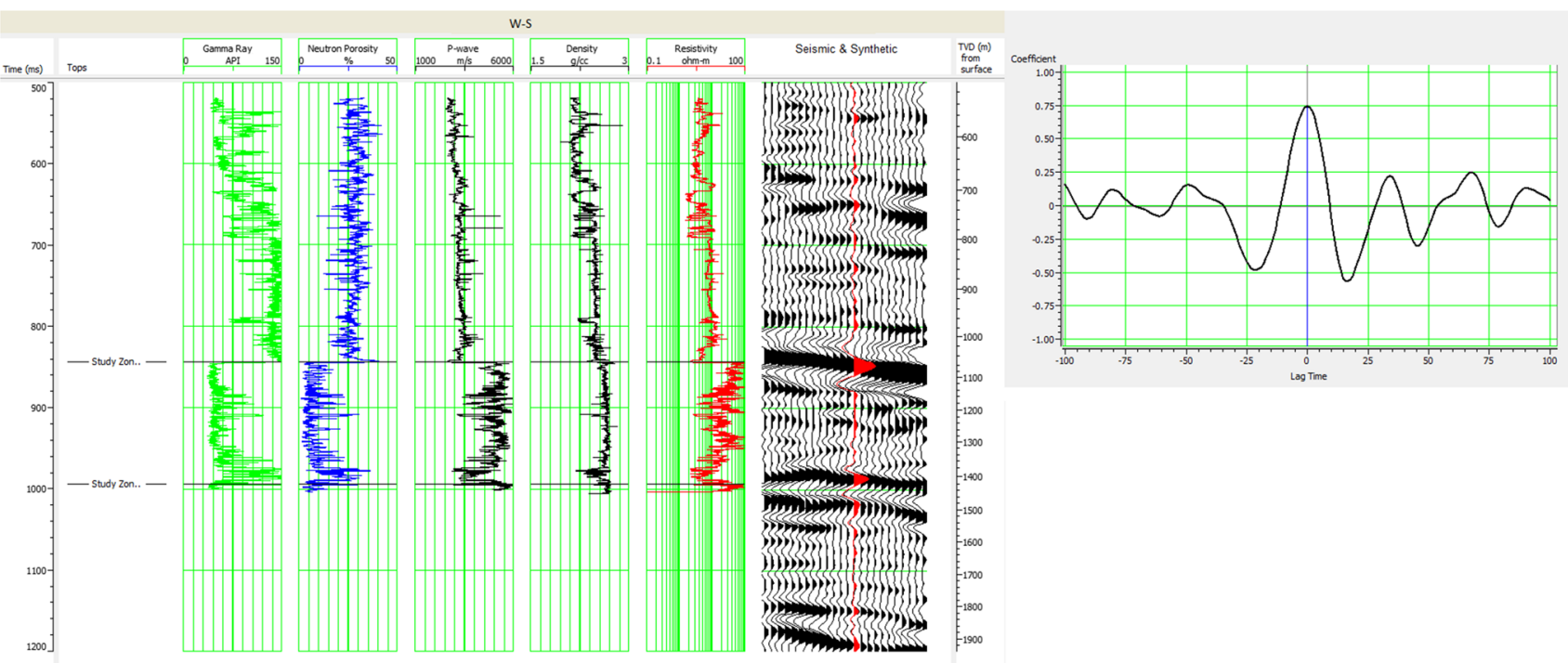

Fig. 4 Well to seismic tie for computation of time to depth relationship and extraction of suitable wavelets in the well W-S of the Bandha region (seismic survey vintage \# 1)

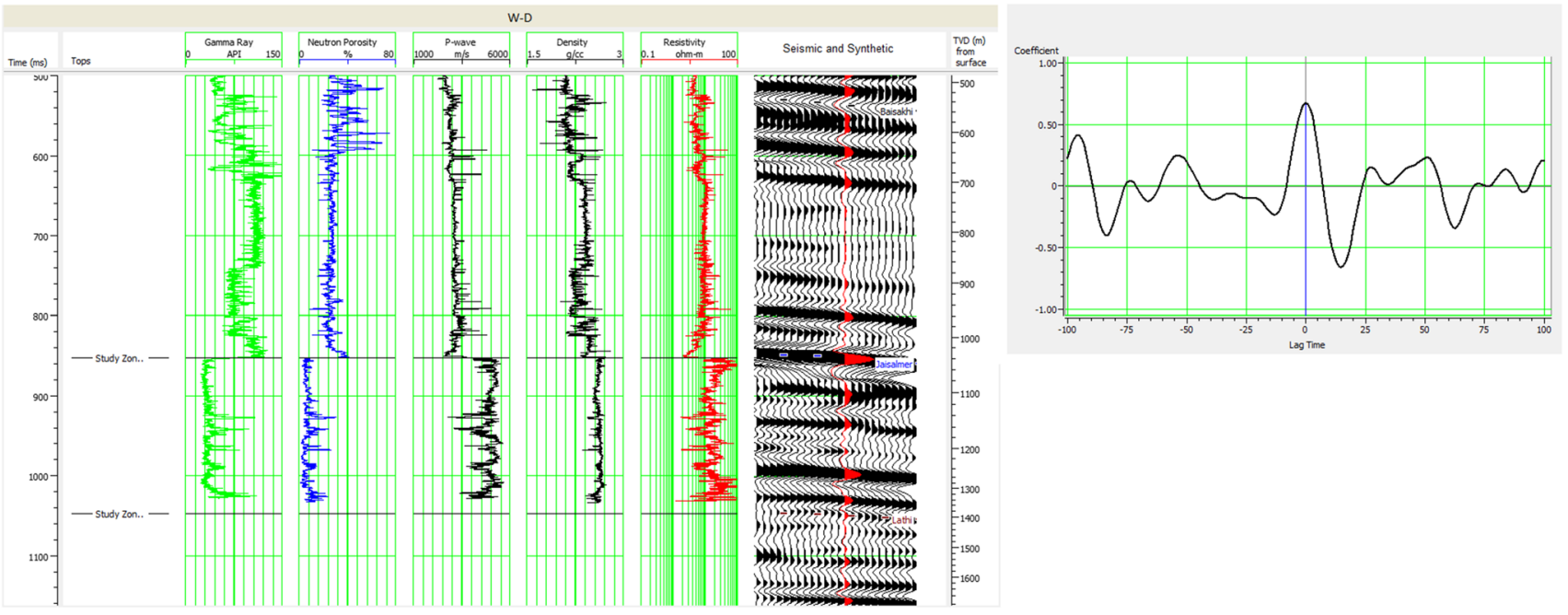

Fig. 5 Well to seismic tie for computation of time to depth relationship and extraction of suitable wavelets in the well W-D of the Bandha region (seismic survey vintage \# 1)

based on geological trend capturing in a specific formation. An improved result has developed between well and seismic data correlation after proper conditioning of well data. A multi-wall cross plot and histogram analysis was performed to identify the lousy section dominated data points in the borehole. In a few parts where the movement of the tools was observed, those data points were eliminated during the conditioning of well log data. In the Jaisalmer Formation, where the logging tool malfunction has influenced log data, those data points have been rectified based on density and velocity relationship. The empirical relationship of Gardner et al. (1974) and Castagna and Backus (1993) used significantly for identifying data trend and predicting unavailable well log data.

In a highly heterogeneous reservoir rock, few limitations have been observed for predicting density log data based on Castagna's empirical relationships (Castagna and Backus 1993).An empirical relationship such as power regression trend between P-velocity and Density in the nearby wells within appropriate study interval and similar lithology was adopted in this study. The modified Gardner's relationship (Eq. 1) was used for predicting density, whereas P-sonic was estimated based on Eq. 2 (Faust 1953) where density data was not available. 

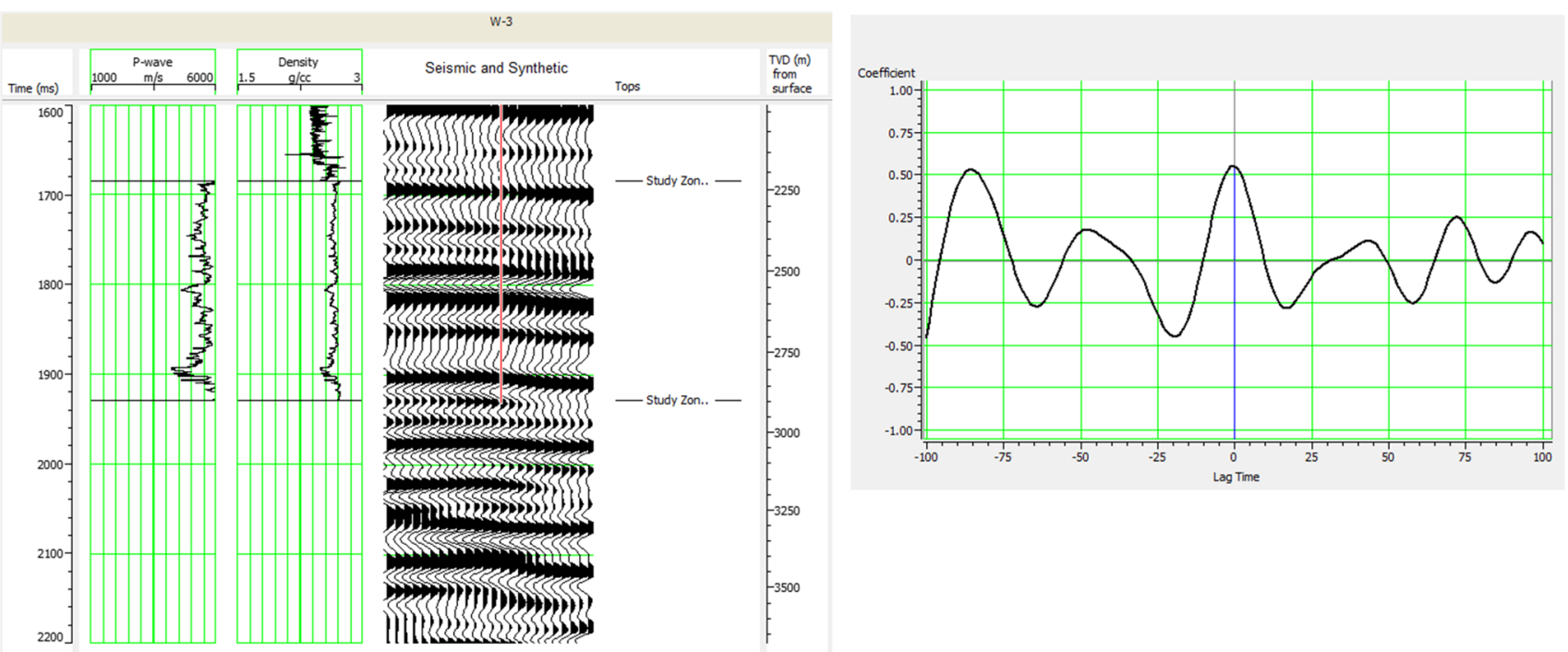

Fig. 6 Well to seismic tie for computation of time to depth relationship and extraction of suitable wavelets in the well W-3 of the Ghotaru region (seismic survey vintage \# 2)
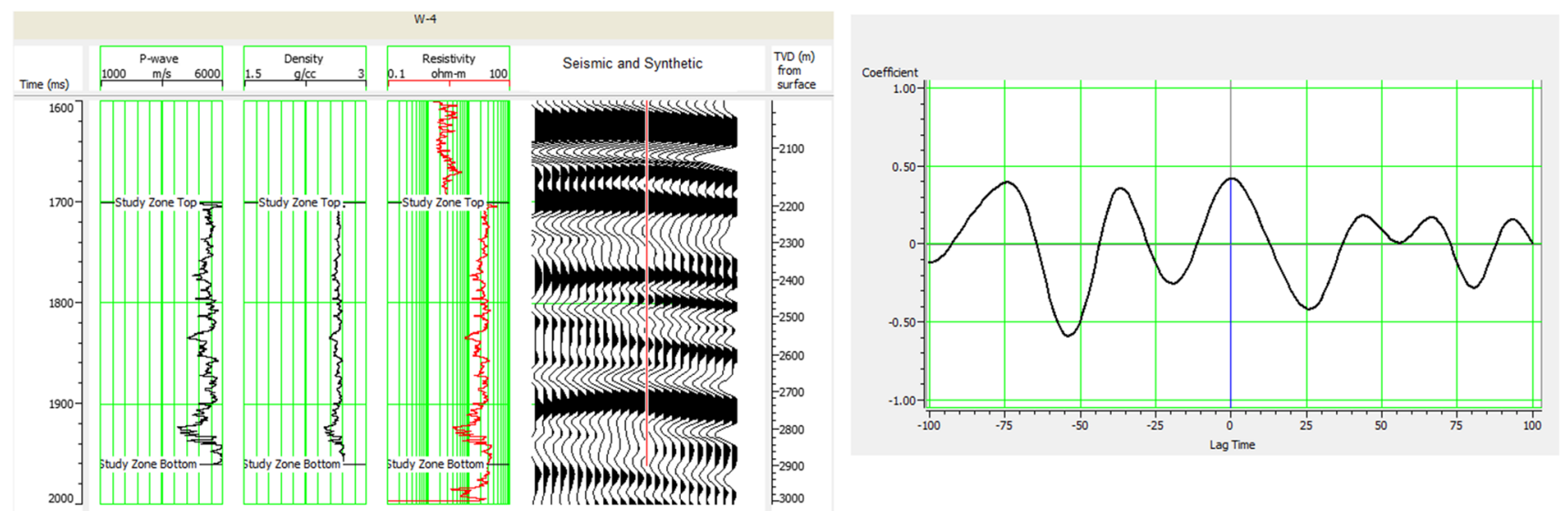

Fig. 7 Well to seismic tie for computation of time to depth relationship and extraction of suitable wavelets in the well W-4 of the Ghotaru region (seismic survey vintage \# 2)

$\rho_{\mathrm{b}}=\mathrm{a} * V_{\mathrm{P}}^{\mathrm{b}}$

a and $\mathrm{b}=$ constant whereas $\rho$ and $V_{\mathrm{P}}$ are the density and P-wave velocity

$V_{\mathrm{P}}=\mathrm{a}(R Z)^{1 / 6}$

$V_{\mathrm{P}}=\mathrm{P}$-wave velocity (in feet); $\mathrm{a}=$ constant; $R=$ resistivity value (in ohm-feet) and $Z=$ depth (in feet).

\section{Modelling of the well log data for estimation of the elastic properties}

The AI (acoustic impedance) property of the limestone reservoir rock of the Jaisalmer Formation was estimated based on P-wave velocity (derived from P-Sonic log) and density log data (Chatterjee et al. 2013) (Chow et al. 2005). The density log data were considered directly from 


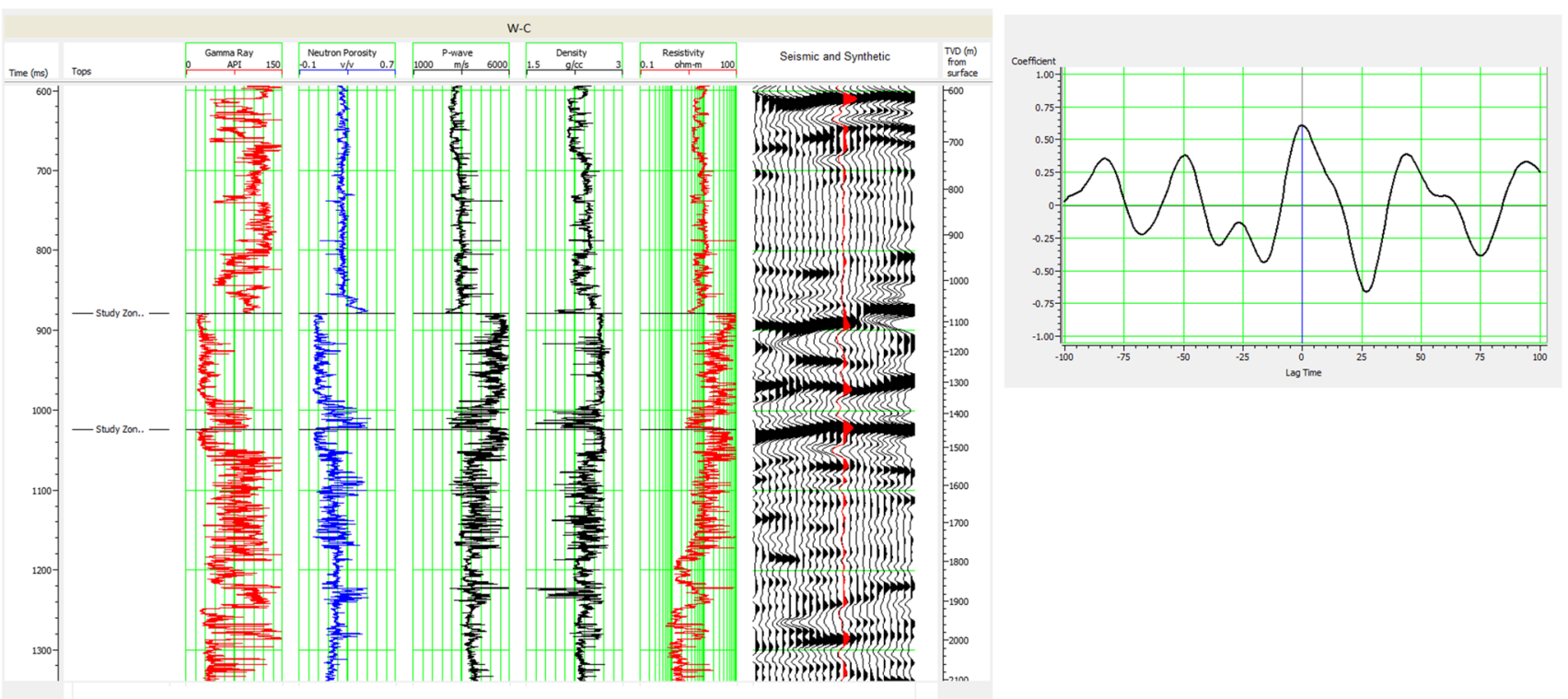

Fig. 8 Well to seismic tie for computation of time to depth relationship and extraction of suitable wavelets in the well W-C of the Bandha region (seismic survey vintage \# 1)

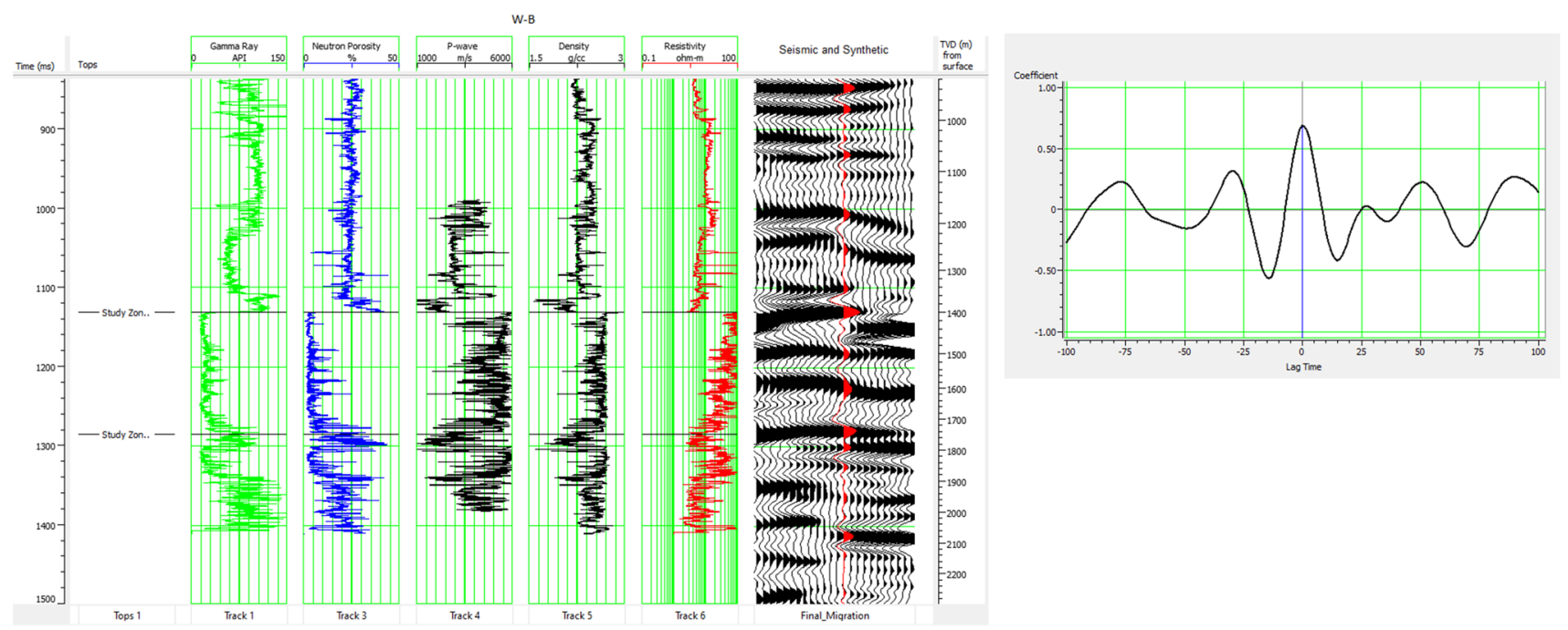

Fig. 9 Well to seismic tie for computation of time to depth relationship and extraction of suitable wavelets in the well W-B of the Bandha region (seismic survey vintage \# 1)

well, whereas, in a few instances, it was estimated based on a transformation relationship. The key lithology of the reservoir for hydrocarbon exploration are identified from the AI property (Taner 2001) (Cemen et al. 2013). It shows a relation between rock property and geophysical data (seismic and well log) derived property. A stable comparison between log derived property, and synthetic model derived property has been performed. The well logbased AI property is known as Zobs.

To determine the acoustic impedance from the well log data, let us assume $\left(\rho_{\mathrm{b}}\right)$ as the bulk density and $(\Delta t)$ as the sonic transit time. The acoustic impedance $(Z)$ of a medium is obtained from the elastic theory is given as,

$$
\begin{gathered}
Z=\frac{\rho_{\mathrm{b}}}{\Delta t} \\
V_{\mathrm{P}}=\frac{1}{\Delta t}
\end{gathered}
$$

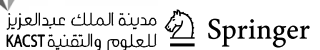




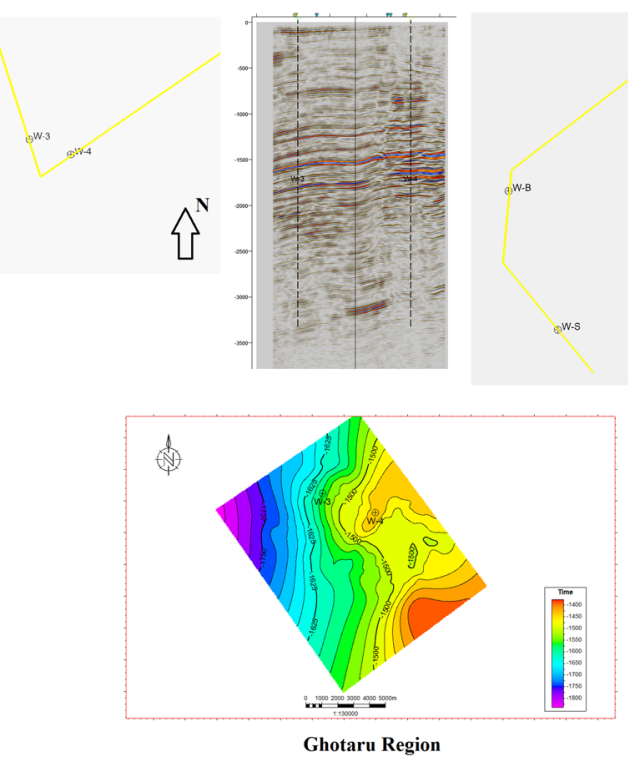

(a)
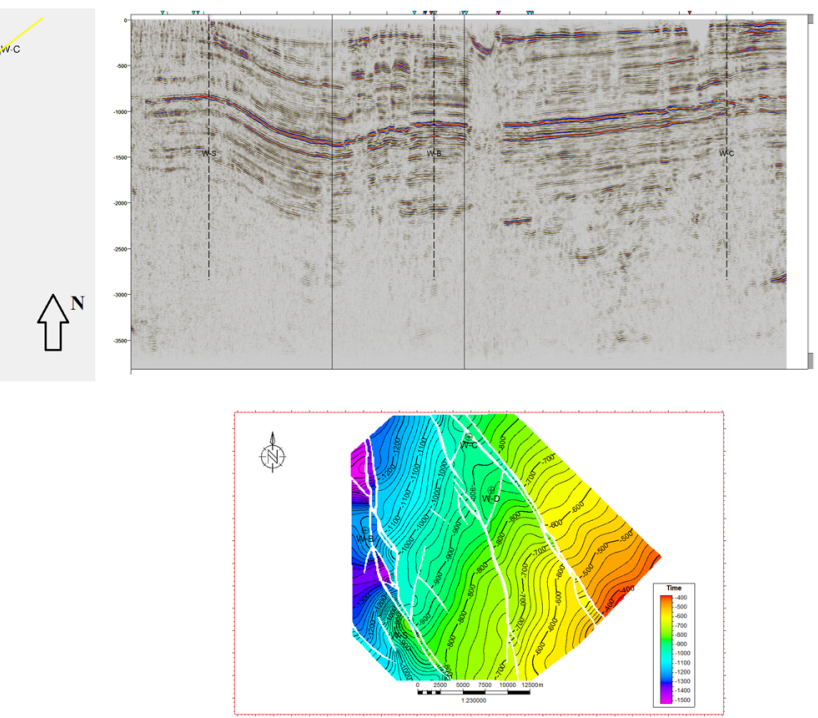

Bandha Region

(b)

Fig. 10 Distribution of the seismic section and structural contour map of the Jaisalmer Formation in the two-study areas-Ghotaru (a) and Bandha (b) regions; geological Ghotaru area is more promising for hydrocarbon exploration

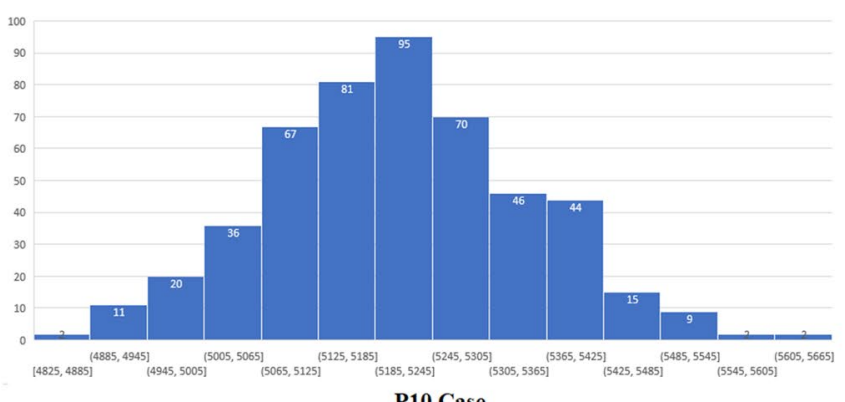

P10 Case

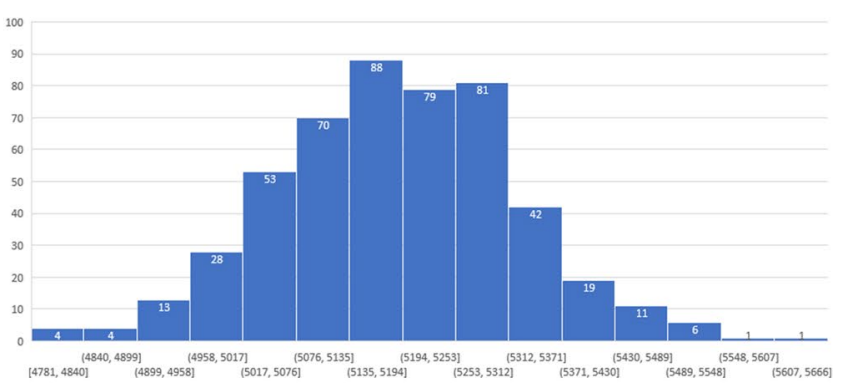

P50 Case

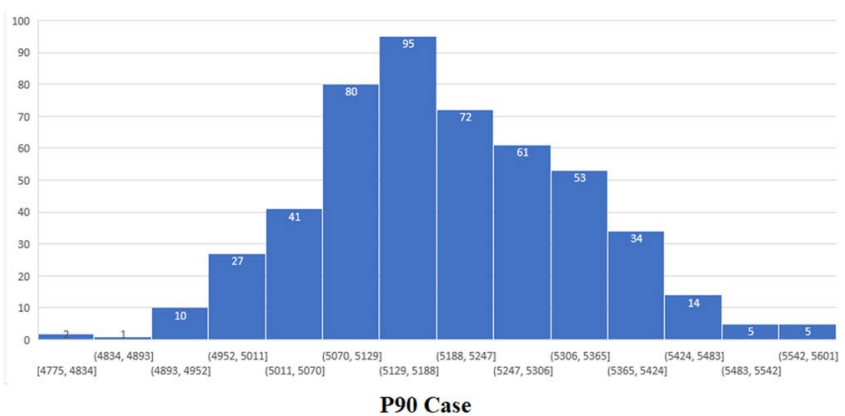

Fig. 11 Capture the Uncertainty of the estimated stacking velocity model based on P10, P50 and P10 analysis

\section{Wavelet extraction}

Wavelet is considered as a convolution operator between seismic data and reflectivity of the surface. Generally, extraction of the wavelet can be performed based on three approaches,
- The linear phase assumes a zero phase.

- Least square where phase assumption is not considered.

- Least square with a constant phase where the assumption of phases is considered based on the correlation between log reflectivity and surface seismic. 


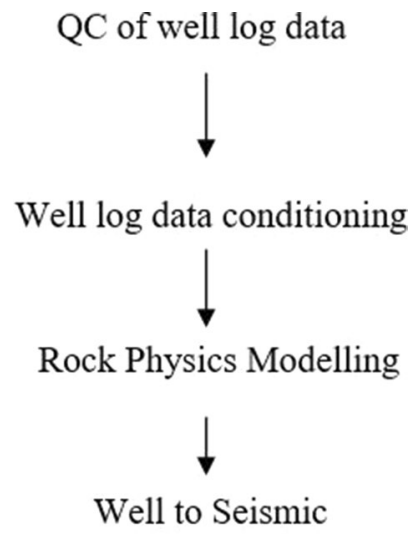

Fig. 12 A summary of the workflow for editing and conditioning of the well $\log$ data

The extracting algorithms are classified into various categories such as analytical, deterministic, statistical and multi-well. Uses of the suitable filter to determine the wavelet plays a crucial role during correlation between well reflection coefficient and seismic traces. Phase and frequency-related information is considered from the inverse filter. Initially, the time delay of the wavelet is eliminated based on bulk shift, and then the wavelet is placed at zero time for further fine-tuning. The application of the inversion process shows further optimisation of the wavelet during sparse spike inversion of the seismic traces near well position (Anitha et al. 2014). In the sparse spike inversion, the least number of acoustic impedance interfaces imitate a seismic trace that models the sub-surface reflectivity.

This study assumes that the sparse reflection coefficient series is associated with the acoustic impedance. It implies that the seismic trace can be modelled with fewer reflection coefficients; only the large impedance contrast (shown by large spikes) is expressive. The original seismic response is generated by the convolution of imitated seismic trace with the wavelet. The aim is to get a high-resolution impedance profile from band-limited seismic data directly connected to rock properties or lithology of the formation. The current analogy for estimating the wavelet from multiple traces with low-frequency information provides better information for inversion with a limited likelihood solution. The current seismic and well log responses support choosing the maximum-likelihood algorithm over a linear programming algorithm to extract the wavelet in this study under a sparse spike inversion process. The integrated response between well $\log$ and seismic data in a specific window has shown a fruitful outcome for choosing an algorithm. The wavelet was estimated during well to seismic tie at each well of the study area, such as vintage \#1) and vintage\#2 in the Jaisalmer Formation (Mitra et al. 1993).

\section{Post-stack seismic inversion}

Post-stack seismic inversion is used to estimate P-impedance (absolute acoustic impedance) from the seismic reflection data. The seismic trace $s(t)$ is the result of the convolution process of the reflectivity series $r(t)$ and wavelet $w(t)$ and some additional noise $n(t)$. Mathematically, the result can be represented (Mangasi and Haris 2018; Chahal and Datta Gupta 2020).

$s(t)=r(t) * w(t)+n(t)$

The acoustic impedance (AI) of the $i$ th layer can be given as follows:

$$
\mathrm{AI}_{i}=\frac{R_{i+1}-R_{i}}{R_{i+1}+R_{i}}
$$

where $R_{i}$ and $R_{i+1}$ are the reflection coefficient of $i$ th and $(i+1)$ th layer, respectively.

In this study, a model-based post-stack inversion has been carried out. It is an iterative modelling process where the geological model is updated and compared from the seismic data to make it better. The generalised linear inversion can mathematically relate to the post-seismic inversion. At the initial stage for the model-based inversion is the generation of the acoustic impedance $\log s$ at the well locations. The algorithm for the inversion process is to modify the P-wave impedance log by minimising the difference between the measured and synthetic seismic data.

Similarly, a good correlation was achieved from the seismic and synthetic model. Figures 4, 5, 6, 7, 8 and 9, shows the correlation between the inverted $\mathrm{P}$-wave impedance and the original log impedance in the Jaisalmer Formation in both the study region. In the post-stack inversion process, the key input is the post-stack seismic data, estimated wavelet and low-frequency model. Most of the challenges during the inversion process lies in the wavelet extraction and building the low-frequency model (LFM). The kriging interpolation method was used in few instances to generate missing values in the well log to integrate with post-stack seismic data for generating LFM. LFM is an essential part of the absolute acoustic inversion process. Seismic-based RMS stacking velocity was available in the coarser grid, converted to the interval velocity based on Dix's empirical relationship. The converted interval velocity downscaled to the seismic grid through consistent horizon interpolation. Elimination of the spurious information and comparison with the same scale seismic velocity, a filter at $1 \mathrm{~Hz}$ was applied over well velocity. The process shows a consistent trend between well and seismic velocity where the seismic interval velocity has been transformed to P-impedance (AI) based on the estimated relationship between P-impedance and velocity at the well level. A compaction trend has been 
observed during conversion with information of 0 to $1 \mathrm{~Hz}$ frequency. The transformed AI was used prior to initiating the inversion process of all full-stack data based on the estimated wavelets. The impedance results from LFM provided information below the seismic bandwidth, and it was guided by the structural and stratigraphic framework based on interpolated structural interpretation. (structural/stratigraphical). The result shows consistency between well derived P-impedance and LFM derived P-impedance.

The current study has been carried out based on the model-based inversion process. A summary of the modelbased inversion process adopted in this study has been below,

1. Acoustic impedance at well was estimated by utilising the data of well log.

2. Horizons and faults in the seismic section were selected to monitor the interpolation and provide structural information for the model between the wells.

3. The acoustic impedance model was initiated based on the interpolation along the interpreted horizons and between the wells.

4. The initial impedance was blocked by utilising identified block size.

5. The statistical wavelet was estimated from the seismic section. The extraction window was within the identified well-based markers such as study zone top and study zone bottom.6. To acquire the artificial seismic trace, the wavelet was convolved with the earth's reflectivity.

6. To reduce the differences between the actual and modelled reflectivity section, the least square optimisation technique was executed. The process was adopted by examining the misfit between the generated trace and the actual trace based on the modification of block size and amplitude variation in the traces.

7. The earlier step was repeated to reduce the misfit coefficient between actual trace and modelled trace (Maurya and Sarkar 2016).

A pictorial representation of post-stack seismic inversion and the model-based seismic inversion has been represented in Figs. 13 and 14, which was adopted during the current study.

\section{Result and discussion}

Mostly the interpreted formations are dipping gently towards the NW direction with some fault closures. We have observed few minor faults in the Jaisalmer Formation, which are sub-parallel to the two major faults, whereas few minor faults strike oblique to these major faults. A clear image of tectonic deformation has been observed in the study area, especially in the western part of the Bandha region. The tectonic history of the study shows the presence of wrench
Fig. 13 A summary of the generalized workflow for conducting a post-stack inversion process

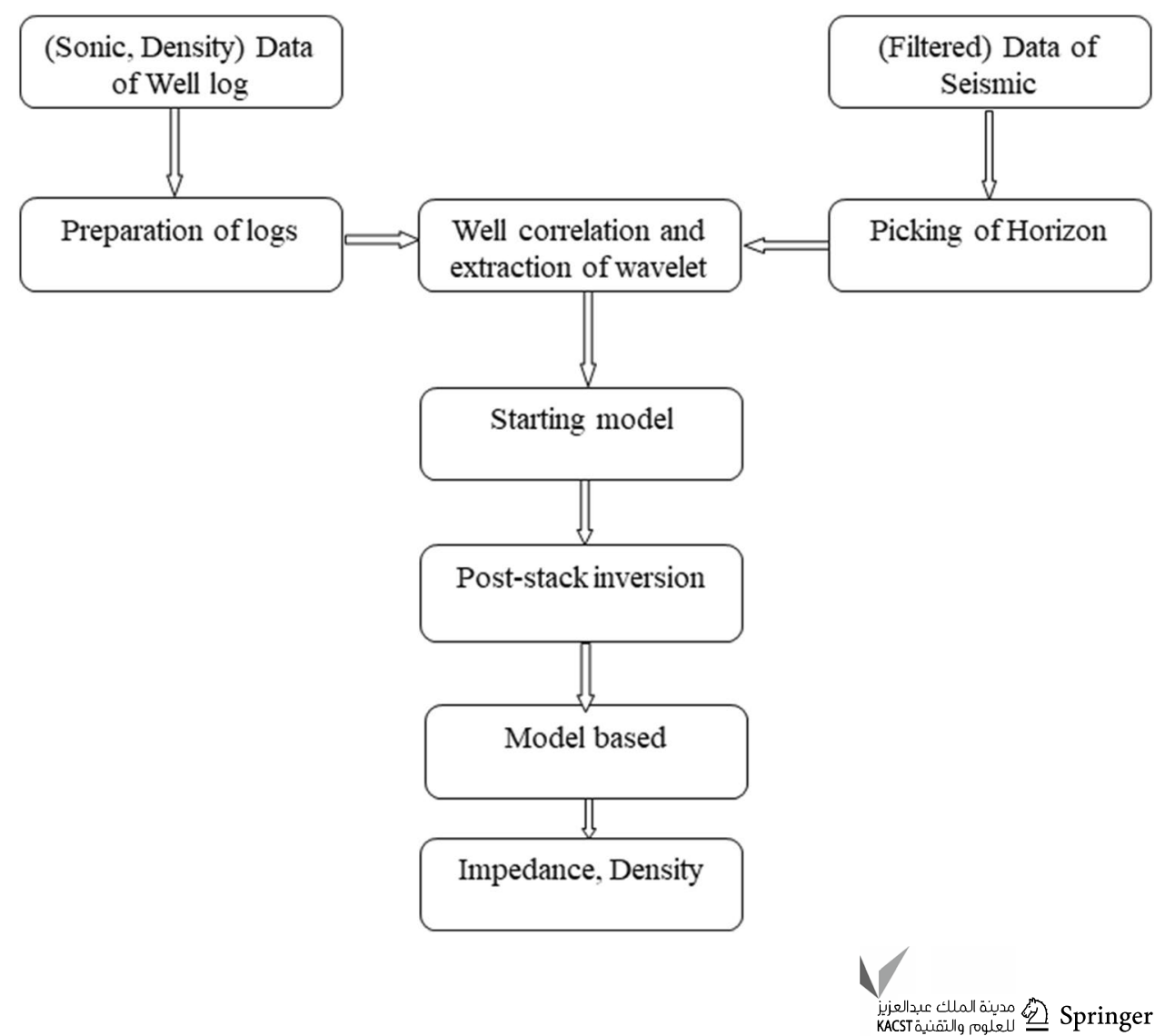


Fig. 14 A summary of the generalized workflow for conducting a model-based post-stack inversion process; incorporation of sensitivity, uncertainty and acceptance of the interim outcomes are the essential functions of the model-based post-stack inversion process

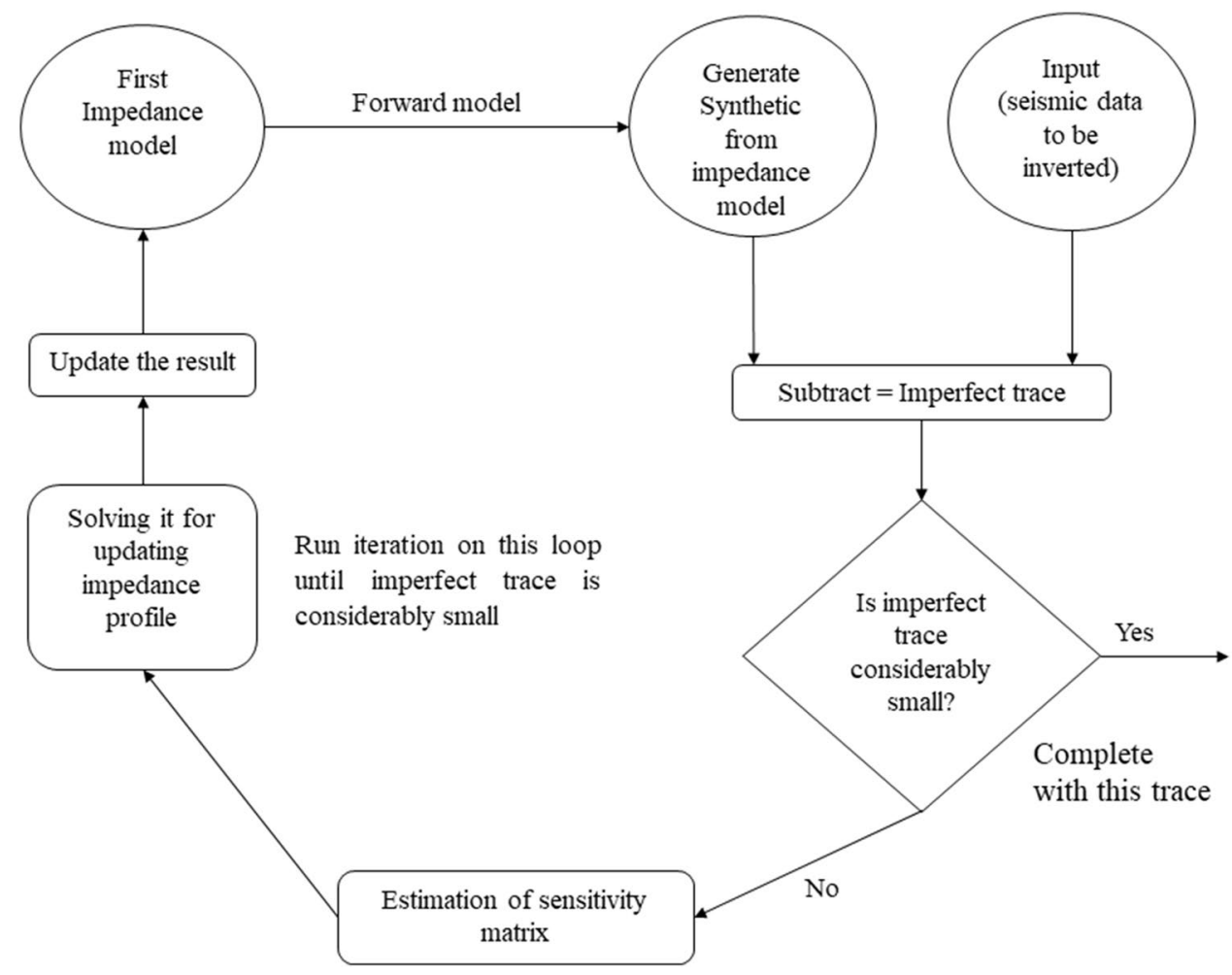

tectonics in this study area during the Late Cretaceous or Early Paleocene age. Two major faults are characterized as a strike-slip fault, which is also known as a wrench and has been expanded towards the NNW-SSE direction. Few minor related faults are sub-parallel and oblique to these major faults. Most of the faults in this area are very high angle with the minor throw. A significant character has been observed in this study area under cratonic to peri-cratonic settings of the Jaisalmer sub-basin where faults nature is varying from normal to reverse along the vertical and horizontal direction. The seismic interpretation in two vintages (Bandha and Ghotaru) shows the carbonated dominated sequences in the Jaisalmer Formation, representing a thickening upward cycle gradually in well log data. The formation comprises major parallel and sub-parallel reflectors with high and low impedance contrast. The most challenging phase in this formation is the frequent variation of the reservoir facies in the lateral direction. These lateral facies variation seems to be controlled by fault control on carbonate sedimentation where relatively raised areas towards the eastern part of the study area had better carbonate platform development. This indicates that faults were active during Jaisalmer formation sedimentation. The Jaisalmer carbonate formation is deposited as a cyclic carbonate platform capped by shale. These cycles possibly represent transgressive para-sequences where the tops most cycle is identified by extensive gamma-ray shale, which was marked as top of the formation. This sequence can be interpreted as MFS (maximum flooding surface), where Baisakhi-Bedesir formation was deposited in high stand system tract (HST). The significant structural deformation in the Jaisalmer Formation has been observed due to the involvement of two major fault blocks in this study area. A significant throw from 800 to $1200 \mathrm{~m}$ has been identified in this study area between Ghotaru and Bandha region (Fig. 3).

A comparative study in the Ghotaru and Bandha region represent different reservoir rock property of the limestone reservoir. The changes in the AI property of the reservoir rocks is due to structural deformation along with the fault plane. The study captures the role of multiple active faults during the deposition of the limestone reservoir formation through interpreting patterns of the appearance in the form of structural and stratigraphy characters. This study shows an essential requirement to identify the potentiality of the hydrocarbon-bearing reservoir (Bastia and Nayak 2006) in these two regions.

The fundamental part of this study has been initiated from well to seismic ties. The statistical wavelets were extracted within the identified zone of interest of the Jaisalmer Formation, which was marked earlier as study zone top and bottom. The depth intervals of these identified zones are different for Ghotaru and Bandha. All wavelets were in zero phase position of the seismic traces. We have observed a maximum $74.6 \%$ (W-S) cross-correlation coefficient in well to seismic tie, whereas the minimum was $42.6 \%$ (W-4). The crosscorrelation coefficient varies from 60 to $65 \%$, which is considerable for this study; however, in the Ghotaru region, the 
Table 2 Characterization of the extracted wavelets

\begin{tabular}{ll}
\hline Well name & Extracted wavelet character \\
\hline W-S & Cross correlation \\
& Phase rotation $=0$ degrees \\
& Zero lag coeff. is maximum \\
& Max coeff. 0.746 \\
& Cross correlation \\
W-D & Phase rotation $=0$ degrees \\
& Zero lag coeff. is maximum \\
& Max coeff. $=0.678$ \\
& Cross correlation \\
W-3 & Phase rotation $=0$ degrees \\
& Zero lag coeff. is maximum \\
& Max coeff. $=0.554$ \\
& Cross correlation \\
W-4 & Phase rotation $=0$ degrees \\
& Zero lag coeff. is maximum \\
& Max coeff. $=0.425$ \\
& Cross correlation \\
& Phase rotation $=0$ degrees \\
W-C & Zero lag coeff. is maximum \\
& Max coeff. $=0.614$ \\
& Cross correlation \\
& Phase rotation =0 degrees \\
W-B & Mero lag coeff. is maximum \\
& Max coeff. =0.689 \\
&
\end{tabular}

cross-correlation values show a lower order (40\% to 55\%) due to the well data quality. Figures 4, 5, 6, 7, 8 and 9 and Table 2 demonstrates the natures of the extracted wavelets from the six wells. Most of the wells in the Ghotaru region are was drilled 40 years earlier, where the limited quality of log data is available, whereas, in the Bandha region, most of the wells drilled recent days advanced and good quality well data has been observed. However, few wells in the Bandha region drilled in earlier days, but the log data quality has been maintained in these wells. In drilled wells of the Ghotaru region, the availability of the data is also limited. In the W-4 well, the reason behind the low cross-correlation coefficient is that all logs are estimated based on the transformation relationship (Gardner et al. 1974) (Faust 1953) (Yalamanchi and Datta Gupta 2021).

In the inversion process, the best fit between original and inverted P-impedance log has been observed in the well W-S, W-3, W-C and W-B where modelled data has also followed convincingly with original traces. All subtle changes have been captured through the inverted P-impedance log in the W-S well, and it follows the trend of the original AI log. In W-D, we have observed a moderate deviation in the top and bottom part of the study zone within the actual and inverted log. In the Ghotaru region, well W-3 produces a comprehensive correlation between inverted and actual log where lithological trend and fluctuations due to the presence of different minerals in the Jaisalmer Formation have been captured. In the other well (W-4) in the Ghotaru region, we have seen a moderate correlation between inverted and actual log where a moderate fluctuation has been observed in the top part and lower part of the study formation. Lower order correlation has been achieved due to the uses of the transformation-based process to generate the required log data. However, it follows the actual geological trend and produces a considerable result. W-C and W-B both produce a distinguish result through the inversion process, and low to high all impedance contrast has been captured as per the geological heterogeneity. A detailed description has been represented in the Fig. 15a-f. A smooth and heterogenous trend has been observed in all inverted log of the well data. W-S, W-B, W-C and W-D wells are placed in the Bandha region where seismic vintage\#1 survey was conducted. We have identified the impedance values of these wells are varying from $2518.86 \mathrm{~m} / \mathrm{s}^{*} \mathrm{gm} / \mathrm{cc}$ to $20,294.4 \mathrm{~m} / \mathrm{s}^{*} \mathrm{gm} /$ $\mathrm{cc}$, whereas in the well W-S, the P-impedance value varies between $2525.07 \mathrm{~m} / \mathrm{s} * \mathrm{gm} / \mathrm{cc}$ and $15,288 \mathrm{~m} / \mathrm{s} * \mathrm{gm} / \mathrm{cc}$ in the study formation. In the Ghotaru region, where vintage\#2 seismic survey was conducted. W-3 and W-4 wells are placed in this region where $\mathrm{P}$-impedance varies between $7358.45 \mathrm{~m} / \mathrm{s}^{*} \mathrm{gm} / \mathrm{cc}$ and $17,894.3 \mathrm{~m} / \mathrm{s}^{*} \mathrm{gm} / \mathrm{cc}$. A consistent impedance variation has been observed in the Ghotaru region. The impedance contrast represents better quality data in the vintage\#2 seismic survey.

Error estimation is an essential part of the seismic inversion process. At the well level, error estimation of the Bandha region (seismic survey vintage \# 1) $13.22 \%$ error has been identified as seismic prediction error, whereas the correlation has been achieved up to $99.21 \%$ (Fig. 16a). For the well W-S and W-C, we are observing a deviation from the synthetic correlation, whereas for W-D, the deviation is less counted, and for W-B well, the estimated P-impedance is draped over synthetic correlation. In the Ghotaru region (seismic survey vintage\#2), 10.92\% seismic prediction error was estimated, whereas correlation is $99.40 \%$ (Fig. 16b).

In the Ghotaru region, W-3 well has a deviation between estimated P-impedance and synthetic correlation, whereas, for $\mathrm{W}-4$, an overlapping between P-impedance and synthetic has been observed. A volumetric difference in the post-stack seismic inversion process of two seismic vintages (Bandha and Ghotaru) has been demonstrated in Fig. 17, where the significance of the residual volume is minor. Fluctuations of the P-impedance in the Bandha region have been observed, whereas, in the Ghotaru region, it is more stable and homogeneous.

A consistent correlation $(>80 \%)$ has been overserved between P-impedance (original) derived in the well and inverted P-impedance (observed) at the well location. Figure $18 \mathrm{a}, \mathrm{b}$ represent both vintages in the study area (Bandha and Ghotaru). In vintage \# 1 the inverted P-impedance mostly varies from $8000 \mathrm{~m} / \mathrm{s} * \mathrm{gm} / \mathrm{cc}$ to $16,000 \mathrm{~m} / \mathrm{s} * \mathrm{gm} /$ cc; a similar inverted P-impedance has been encountered

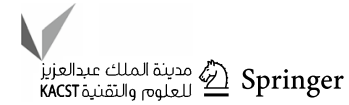




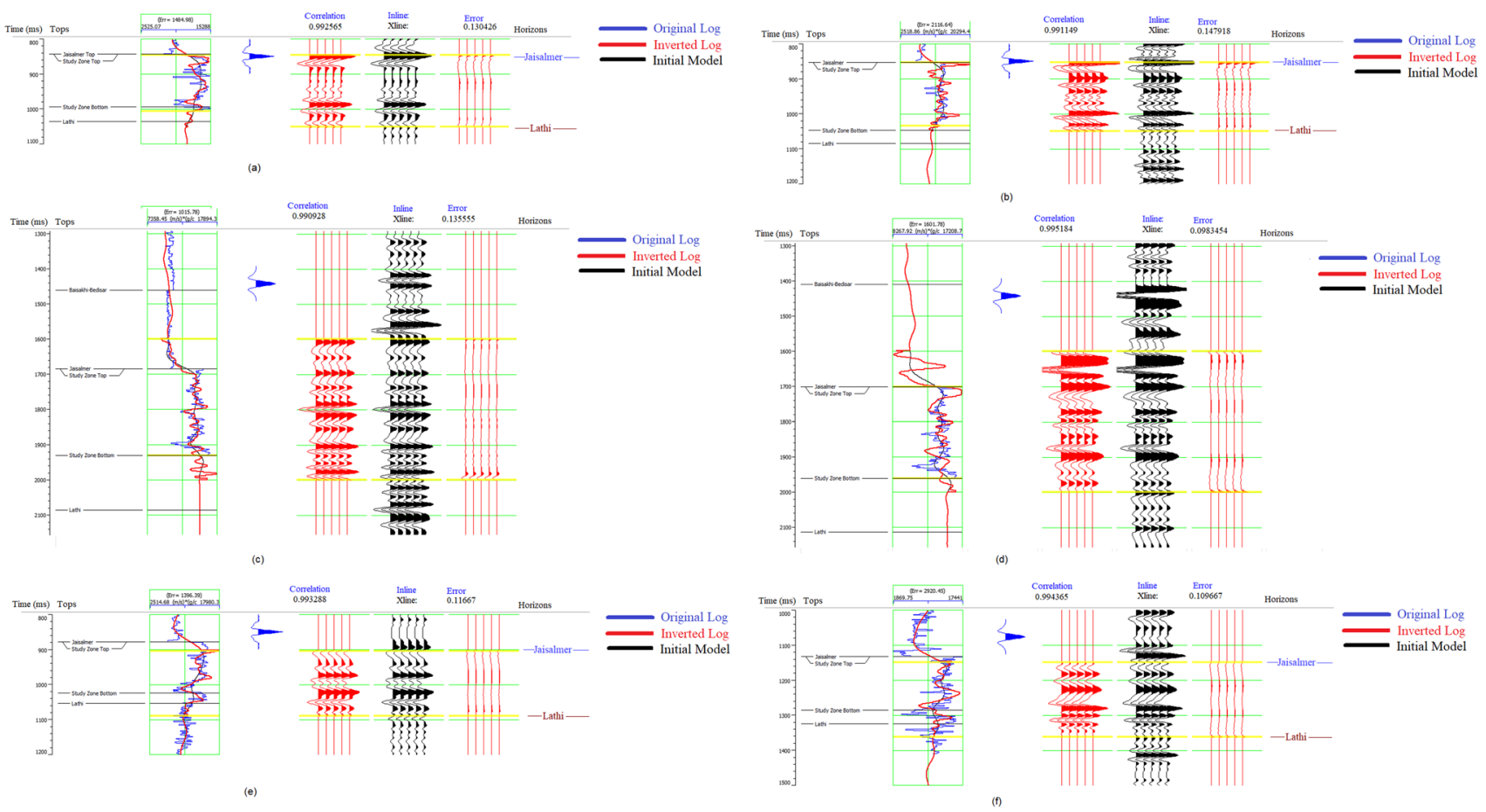

Fig. 15 A comparison study of the inversion process in well locations was conducted-based original log, inverted log and initial model to capture the geological trend based on inversion outcome; a W-S; b W-D; $\mathbf{c ~ W - 3 ; ~ d ~ W - 4 ; ~ e ~ W - C ; ~ a n d ~ f ~ W - B ~}$

in the vintages \# 2 zone where P-impedance mostly varies from $9000 \mathrm{~m} / \mathrm{s} * \mathrm{gm} / \mathrm{cc}$ to $17,000 \mathrm{~m} / \mathrm{s} * \mathrm{gm} / \mathrm{cc}$. A distinct separation has been observed in the vintage \# 1 (Bandha) area, where two prominent zones are identified from inverted P-impedance analysis. In one zone, P-impedance varies from $8000 \mathrm{~m} / \mathrm{s} * \mathrm{gm} / \mathrm{cc}$ to $12,000 \mathrm{~m} / \mathrm{s} * \mathrm{gm} / \mathrm{cc}$, whereas in the second zone inverted P-impedance varies from $13,000 \mathrm{~m} / \mathrm{s}$ $* \mathrm{gm} / \mathrm{cc}$ to $16,000 \mathrm{~m} / \mathrm{s} * \mathrm{gm} / \mathrm{cc}$. We did not identify any multiple zones in vintage \# 2 (Ghotaru area) in this analysis; most of the data points lies between $12,500 \mathrm{~m} / \mathrm{s} * \mathrm{gm} /$ $\mathrm{cc}$ and $17,000 \mathrm{~m} / \mathrm{s} * \mathrm{gm} / \mathrm{cc}$. The analysis shows a considerable correlation between two vintages in the high impedance limestone lithofacies of the Jaisalmer Formation.

Figure 19 shows the distribution of P-impedance in the Jaisalmer limestone reservoir in the Bandha region. An arbitrary section has been developed to represent the subsurface geological strata of the Jaisalmer Formation. The section represents the presence of multiple high angle faults in the study formation. These minor faults are sub-parallel and oblique to the significant wrench faults in the study area. The wells W-S, W-D and W-C, have been drilled in the high impedance limestone lithofacies where W-B has been drilled comparatively low impedance limestone. The P-impedance section shows the abrupt changes in the pattern of the limestone lithofacies. In W-S well, limestone facies are highly discrete and missed the limestone reservoir target during drilling, whereas in W-D well, the reservoir lithofacies is thin, and the well was drilled edge of the facies. A discrete and little extension of limestone lithofacies have been observed for the well W-C. The most prolific limestone reservoir lithofacies has been identified in the W-B well. The surrounding of the W-B well is highly tectonically active. Figure 20 shows the outcome of the post-stack inversion in the Ghotaru region, where a consistent distribution of the p-impedance has been observed. Prominent structural deformation is missing in the arbitrary section of the p-impedance in the Ghotaru area, and a comparatively high P-impedance of the limestone is observed here. The p-impedance section shows a distinct change of the lithofacies in the Jaisalmer Formation of the Ghotaru region.

The outcome of the post-stack inversion in the form of P-impedance has been constructed based on LFM, bandpass and high-frequency content. The overall seismic-based P-impedance shows comparatively low frequency than wellbased P-impedance. However, analysis of the low-frequency trend is essential to capture subtle changes of the reservoir lithofacies based on AI property. The depth of the target formation in this study varies from 1200 to $1577 \mathrm{~m}$ in MD in the Bandha region (seismic survey vintage \# 1) and for Ghotaru region (seismic survey vintage \# 2) it varies from 2200 to $2900 \mathrm{~m}$ in MD. All wells such as W-C, W-B, W-S, and W-D in the Bandha region show a considerable downward P-impedance trend in the seismic scale. Well-based computed P-impedance has been compared to the outcome 

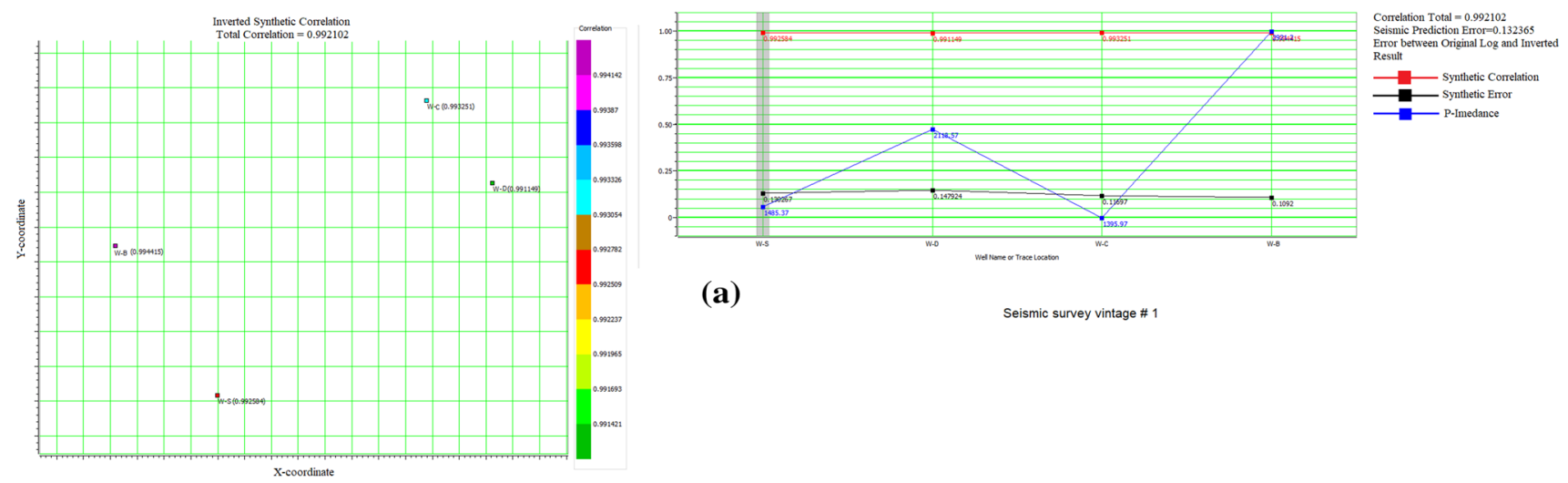

(a)
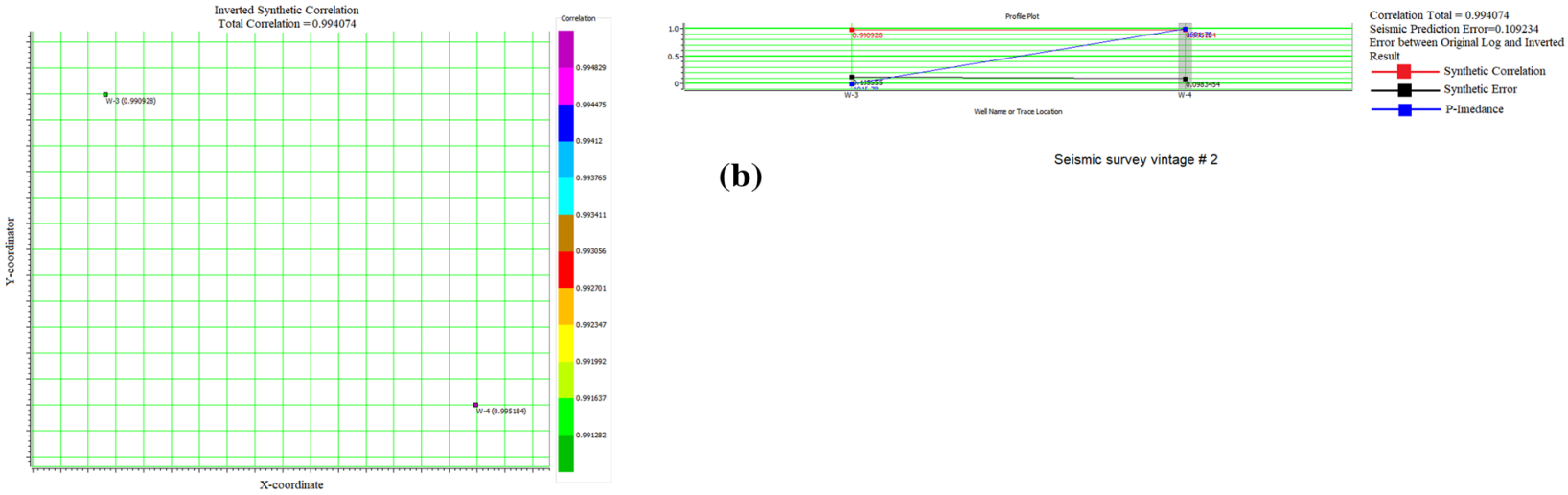

(b)
Fig. 16 Correlation and seismic prediction error analysis of the Poststack inversion process synthetic correlation, synthetic error and P-impedance; $\mathbf{a}$ analysis in the Bandha area (seismic survey vintage

of the seismic-based post-stack inversion based on extraction of the $\log$ at the well location (Fig. 21a). In the final P-impedance volume, the AI value varies from $5000 \mathrm{~m} / \mathrm{s}$ * $\mathrm{gm} / \mathrm{cc}$ to $18,0000 \mathrm{~m} / \mathrm{s} * \mathrm{gm} / \mathrm{cc}$, and a concentration of a single cluster has been observed in this analysis. A significant correlation has been observed between well-based result and seismic-based result. A cross plot between these two parameters have been developed. The plot shows a linear relationship between the $\mathrm{P}$-wave impedance seismic and $\mathrm{P}$-wave impedance log. The linear relation is given by an equation, which is given as follows (Fig. 20b);

$y=0.752957 x+2343.2$

where $y=\mathrm{AI}$ (P-wave acoustic impedance from seismic) and $x$ is the AI (P-wave acoustic impedance from four log). The coefficient of correlation is 0.832316 .

In the Ghotaru region (seismic survey vintage \# 2), the target depth of the limestone formation varies from 2200 to $2900 \mathrm{~m}$ in $\mathrm{MD}$, the comparison between seismic-based P-impedance and well-based P-impedance has been mentioned where AI values vary from $9000 \mathrm{~m} / \mathrm{s} * \mathrm{gm} / \mathrm{cc}$ to $17,0000 \mathrm{~m} / \mathrm{s} * \mathrm{gm} / \mathrm{cc}$. A comprehensive correlation between
1) with four wells; $\mathbf{b}$ analysis in the Ghotaru area (seismic survey vintage 2) with two wells

these two parameters has been observed where all subtle changes have been captured. Two prominent clusters with distinct a separation of P-impedance have been identified in this analysis of the Ghotaru region such as from $9000 \mathrm{~m} / \mathrm{s}$ $* \mathrm{gm} / \mathrm{cc}$ to $12,0000 \mathrm{~m} / \mathrm{s} * \mathrm{gm} / \mathrm{cc}$ and $13,000 \mathrm{~m} / \mathrm{s} * \mathrm{gm} / \mathrm{cc}$ to $16,0000 \mathrm{~m} / \mathrm{s} * \mathrm{gm} / \mathrm{cc}$. The comparatively high impedance limestone is most prolific for hydrocarbon exploration. A convincing correlation ( $>90 \%$ ) has been achieved based on the comparative analysis from the cross plot of well-based and seismic-based P-impedance. The relation between these two parameters have identified as

$y=0.847805 x+1805.3$

where $y=\mathrm{AI}$ (P wave acoustic impedance from seismic) and $x$ is the $\mathrm{AI}$ ( $\mathrm{P}$ wave acoustic impedance from two $\log$ ). The coefficient of correlation is 0.901068 .

The variation of the AI properties with the depth of the two regions (Ghotaru and Bandha) have been captured through cross plot analysis.

The Jaisalmer Formation in the Ghotaru region is on the downthrown side compared to the Bandha region at the range of $800 \mathrm{~m}$ to $1200 \mathrm{~m}$. In the first part of the analysis 


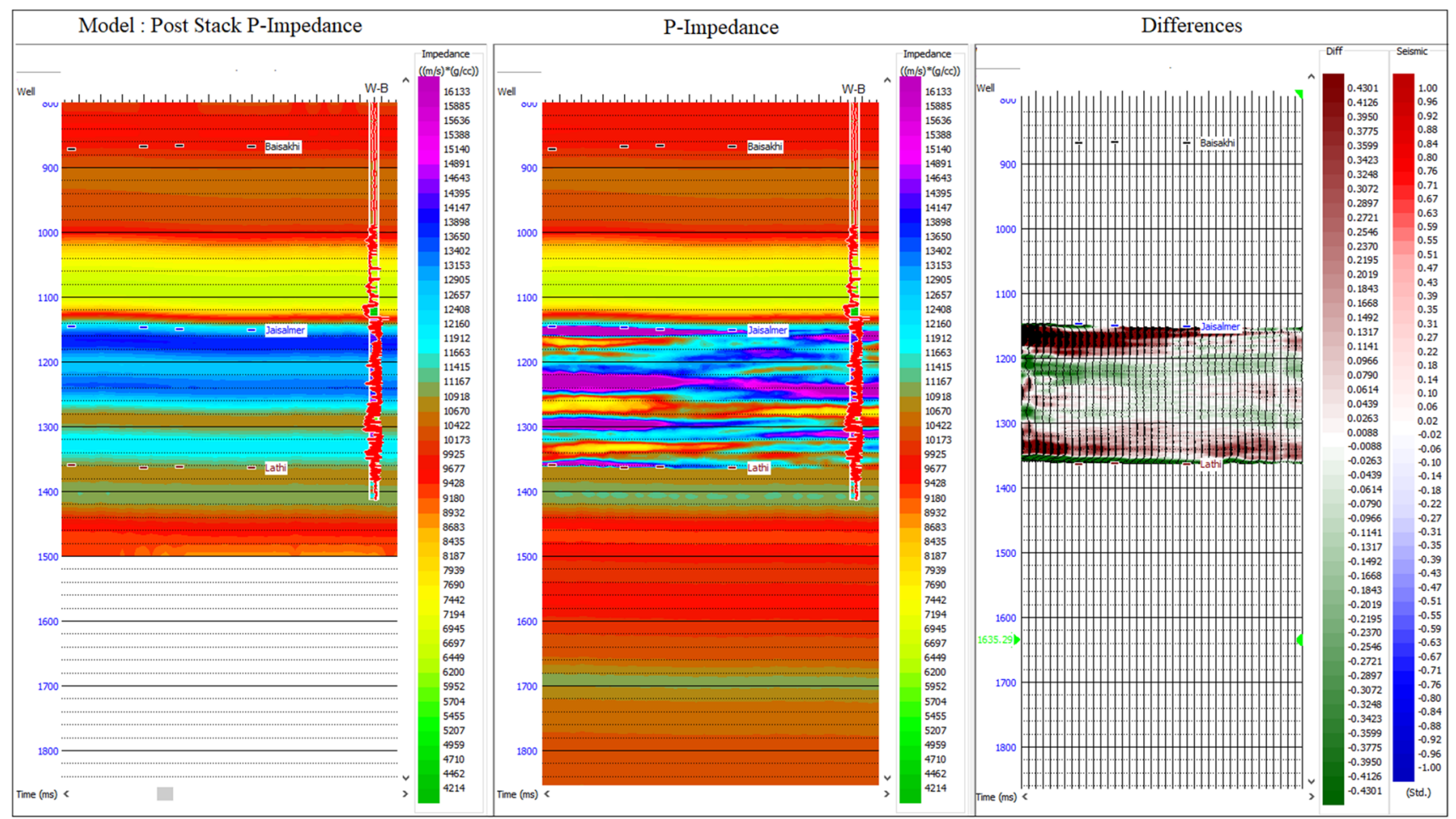

Seismic survey vintage \# 1

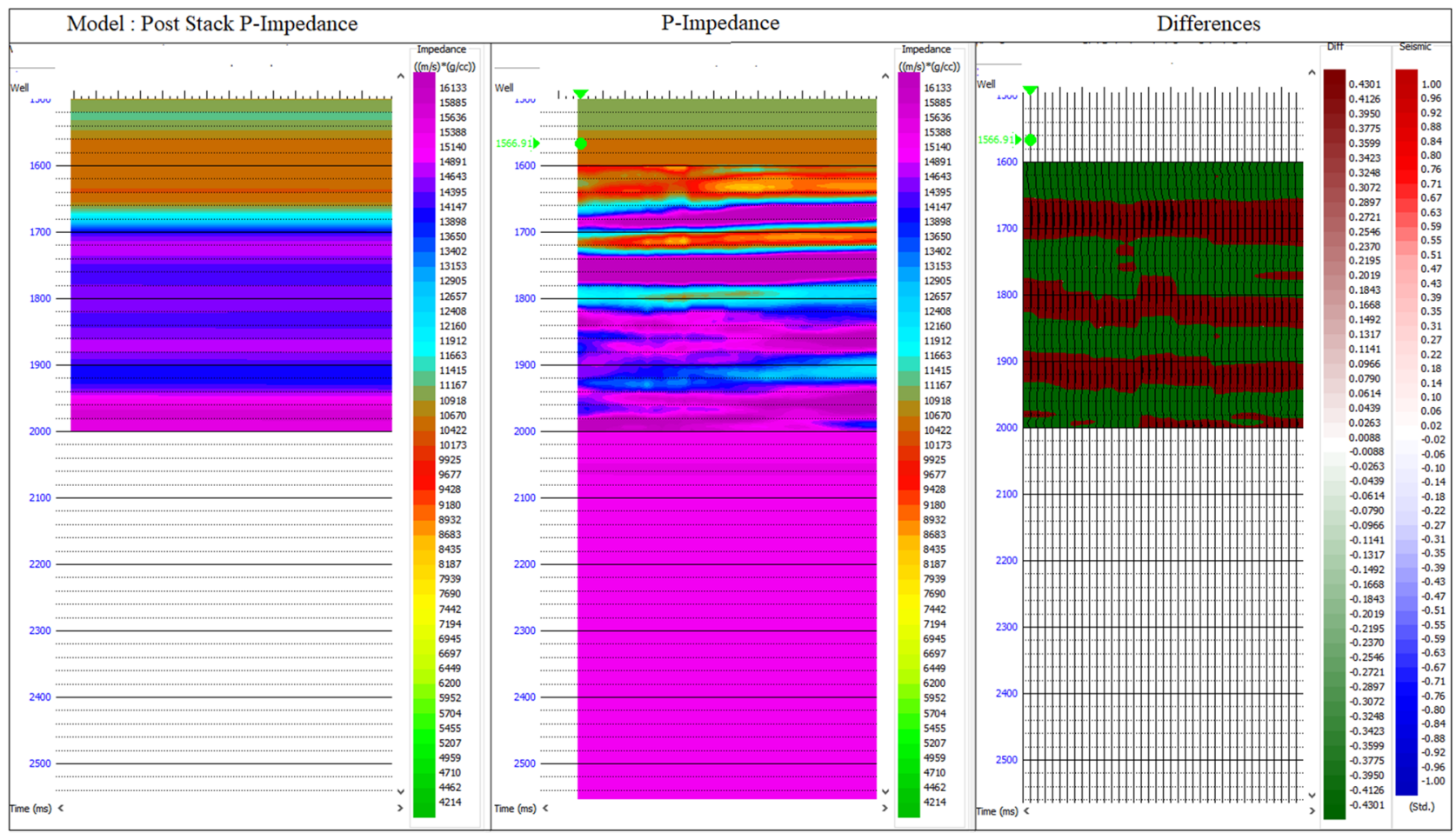

Seismic survey vintage \# 2

Fig. 17 Comparison analysis of the Post-stack inverted volume and residual volume in the Bandha (vintage \# 1) and the Ghotaru region (vintage \#2); analysis shows higher correlation and minimum residual outcome 


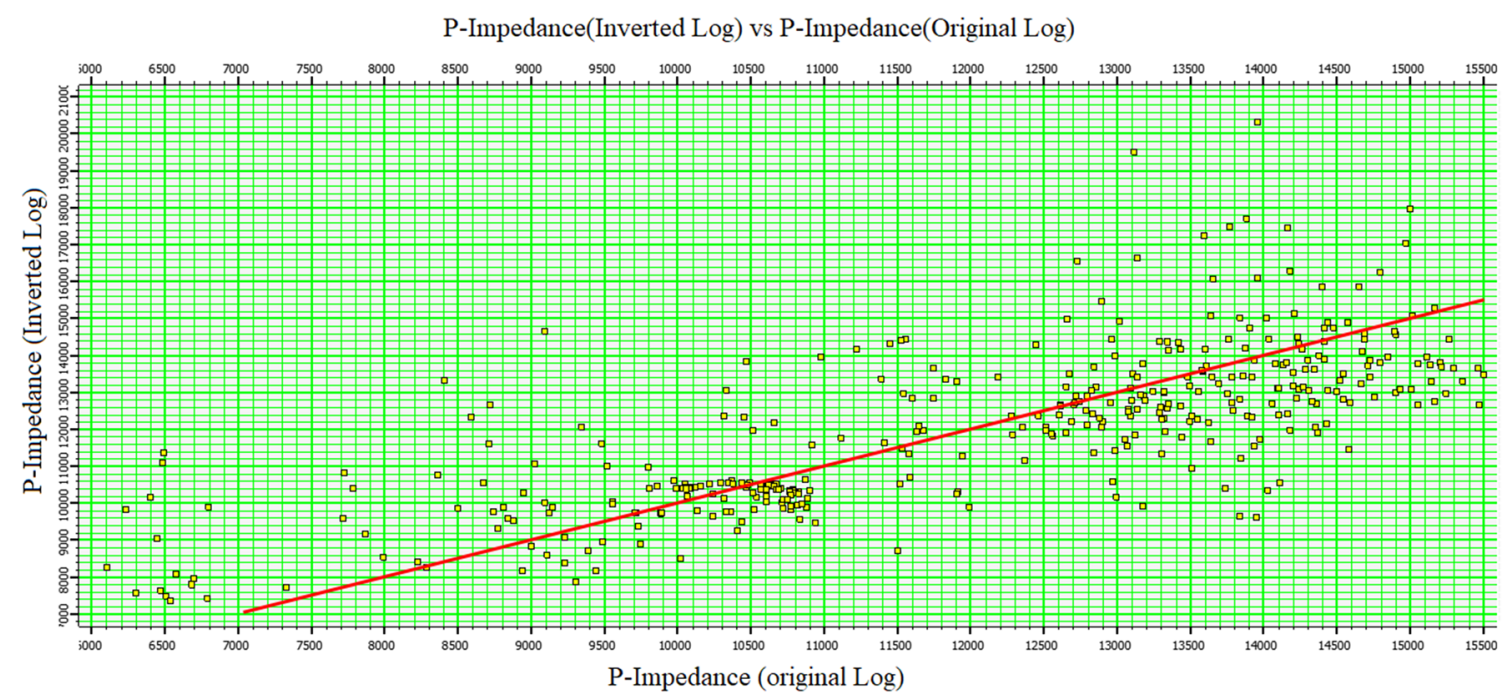

(a)

Seismic survey vintage \#1

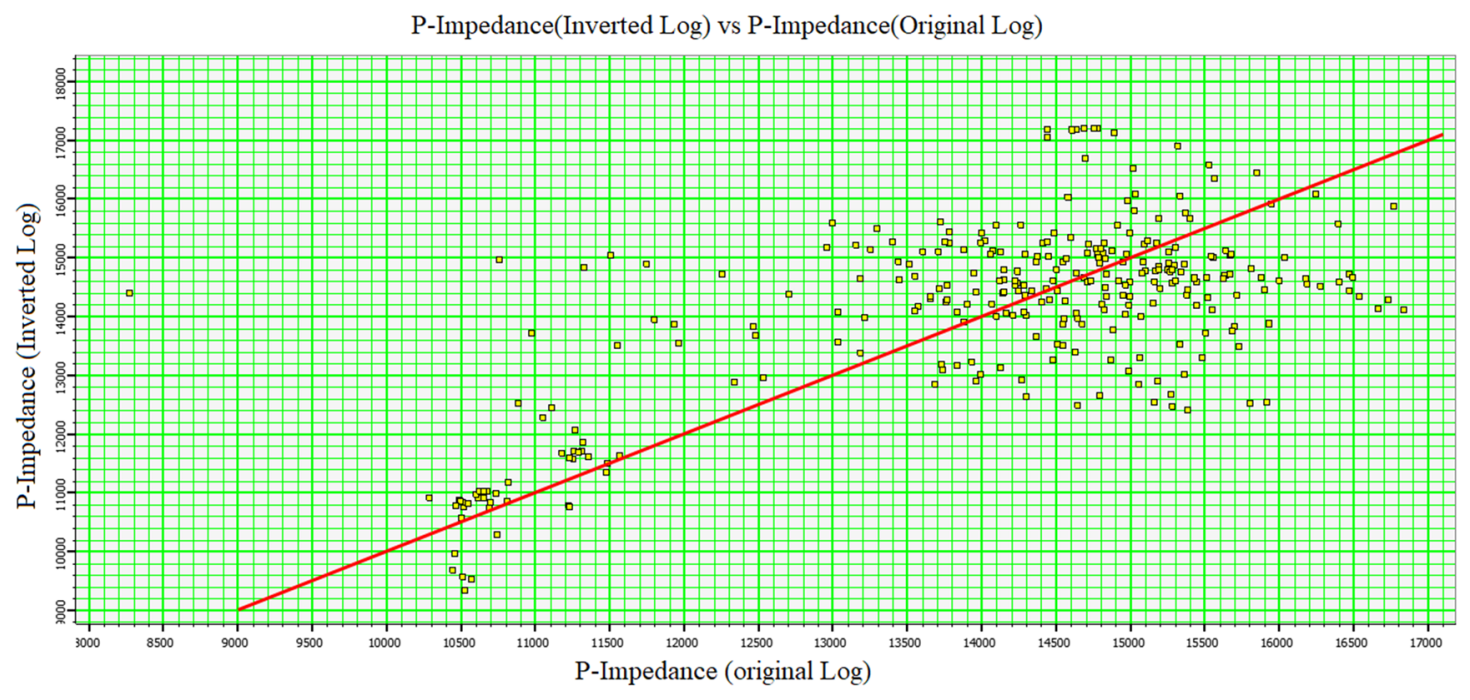

(b)

Seismic survey vintage \#2

Fig. 18 A comparison study has been carried out between actual P-impedance and inverted P-impedance (observed) based on cross plot analysis in the study wells; the study has been conducted in both seismic vintages (Bandha and Ghotaru) and produces considerable correlation

(Fig. 22a), P-impedance and inverted P-impedance has been compared to variation of depth in the limestone formation. A subtle contrast in the P-impedance of the limestone lithofacies has been in the Ghotaru region. The second part of the analysis (Fig. 22b) has been conducted between seismicbased P-impedance and well-based P-impedance with the variation of depth where a similar picture of high impedance limestone in the Ghotaru region has been captured. This high impedance limestone is not present in the Bandha region.

A separation between comparatively low impedance limestone and high impedance limestone has been observed distinctly in the Ghotaru region; however, this separation is not available in the Bandha region along with the discrete nature of the lithofacies. Jaisalmer limestone is a tight reservoir, and the lateral position of hydrocarbon-bearing limestone reservoir lithofacies changes frequently. The nature of the limestone shows the possibility for the presence of hydrocarbon in the high impedance lithofacies. The unsuccessful results in the W-S, W-C, W-D are examples of this challenging architecture of the reservoir in spite of drilling in comparatively high impedance limestone. The $\mathrm{W}-\mathrm{B}$ was drilled in the comparatively low impedance in the region lithofacies; however, success was not observed. Variation of the P-impedance in both areas (Ghotaru and Bandha) has been captured through uncertainty analysis based on P10, P50 and P90 analysis. After analysis of all cases, the minimum and 


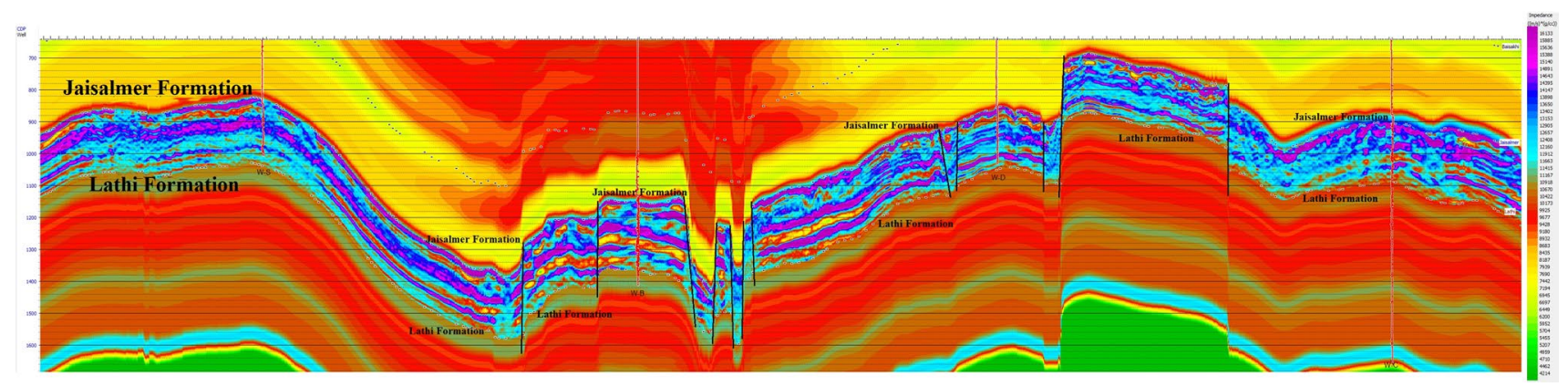

Fig. 19 Final outcome of the inverted P-impedance seismic volume in the Bandha area (seismic survey vintage \# 1); a highly faulted and structural deformed inverted section is observed through four wells (W-S, W-B, W-C and W-D) in for of arbitrary section

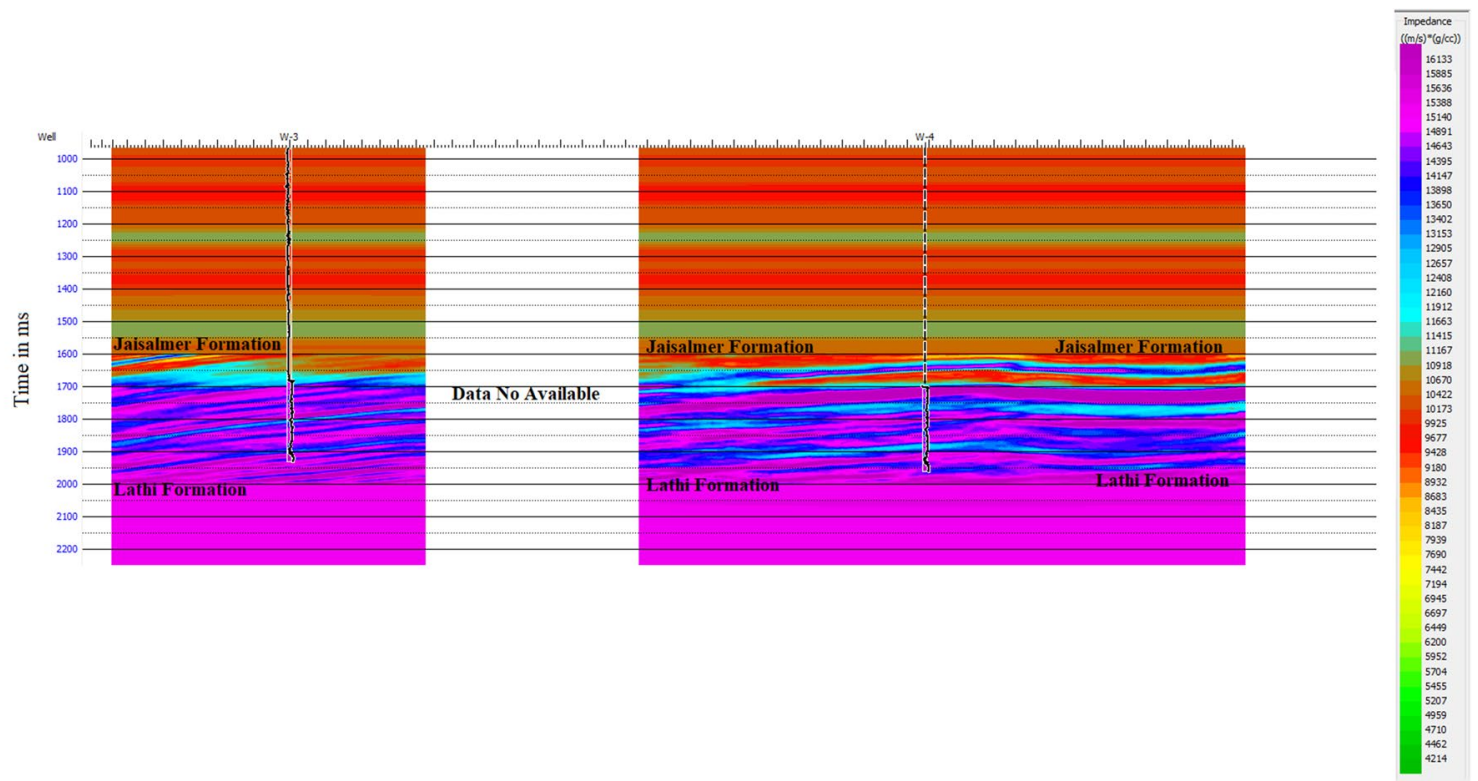

Fig. 20 Final outcome of the inverted P-impedance seismic volume in the Ghotaru area (seismic survey vintage \# 2); comparatively flat and high homogeneity has been observed in the inverted section which is observed through two wells (W-3, and W-4) in for of arbitrary section

maximum values of P-impedance vary between $9674 \mathrm{~m} / \mathrm{s}$ * $\mathrm{gm} / \mathrm{cc}$ and $15,585 \mathrm{~m} / \mathrm{s} * \mathrm{gm} / \mathrm{cc}$ (Fig. 23).

In this kind of reservoir, separation of the reservoir and non-reservoir facies is a big challenge. Tectonic activity plays a crucial role in building this kind of depositional setup where high and low impedance sediments overlap. In the Bandha region, this kind of challenges has been observed. All impedances of the limestone are clubbed together, and the separation of hydrocarbon-bearing lithofacies in study formation is challenging.

The motivation of this study was to identify the differences of limestone sediment nature based on P-impedance property due to tectonic activity where sediments were deposited in the same Jurassic age in a broader sense. Bandha region highly affected by strike-slip faults, and significant lithofacies changes based on fault plane movement has been identified in the Jaisalmer limestone formation through capturing the variation of limestone impedances.

\section{Conclusion}

The primary objective of the current study was to capture the variation of the nature of the limestone in the Jaisalmer Formation based on P-impedance changes. The comparative analysis was carried out because of success in hydrocarbon discovery from the upper geological formation such as Cretaceous and Tertiary age sediments in the Ghotaru region. We have also observed an encouraging fluorescence test in the top of the Jaisalmer Formation of 

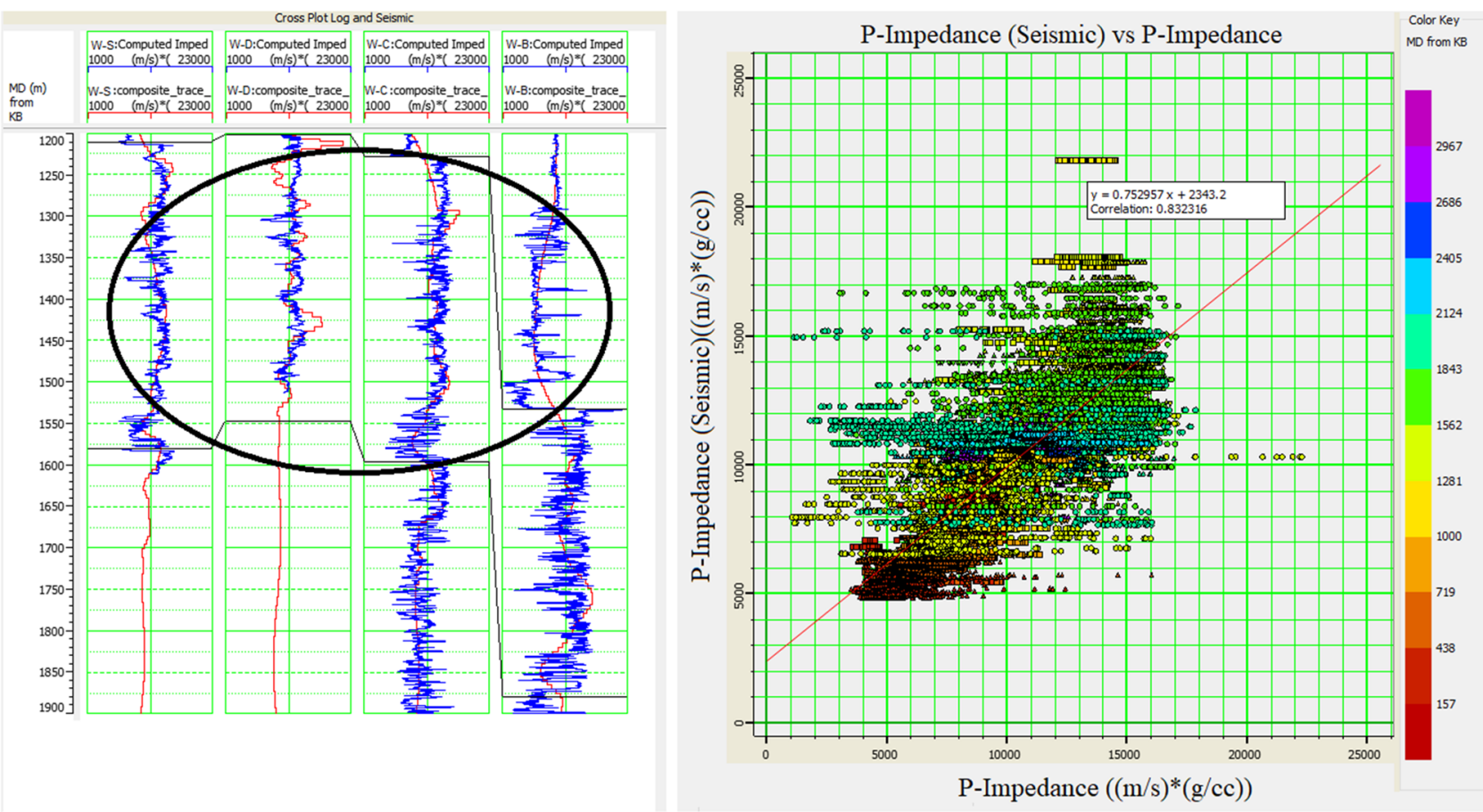

(a)

Seismic survey vintage \# 1
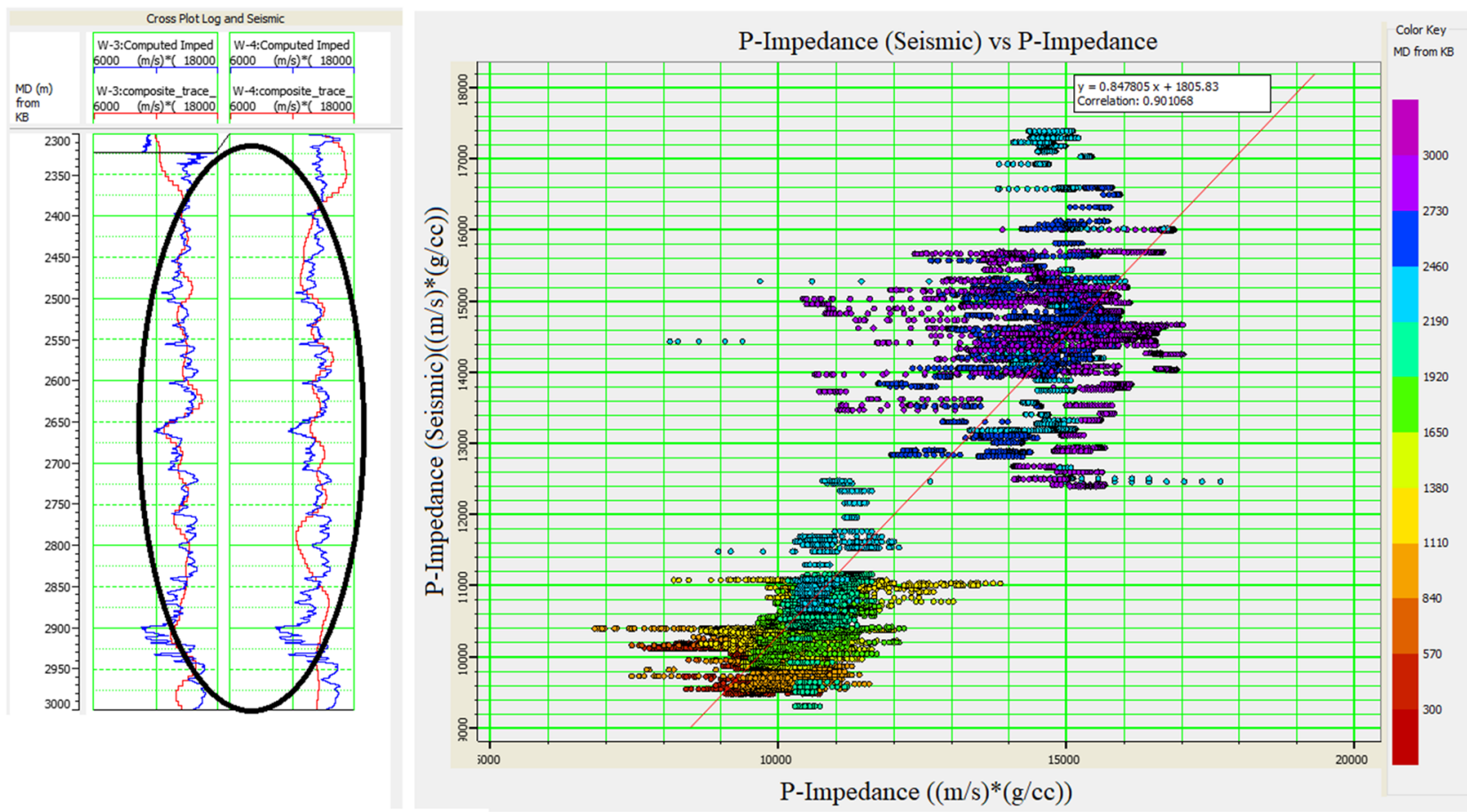

(b)

Seismic survey vintage \# 2

Fig. 21 A comparison between well-based P-impedance log and P-impedance extracted at the well location after Post-stack inversion; a analysis carried for Bandha region (seismic survey vintage \#1); b analysis carried for Ghotaru region (seismic survey vintage \#2); a high and low P-impedance separation has been observed in the Ghotaru region, whereas in the Bandha region it is single clustered 


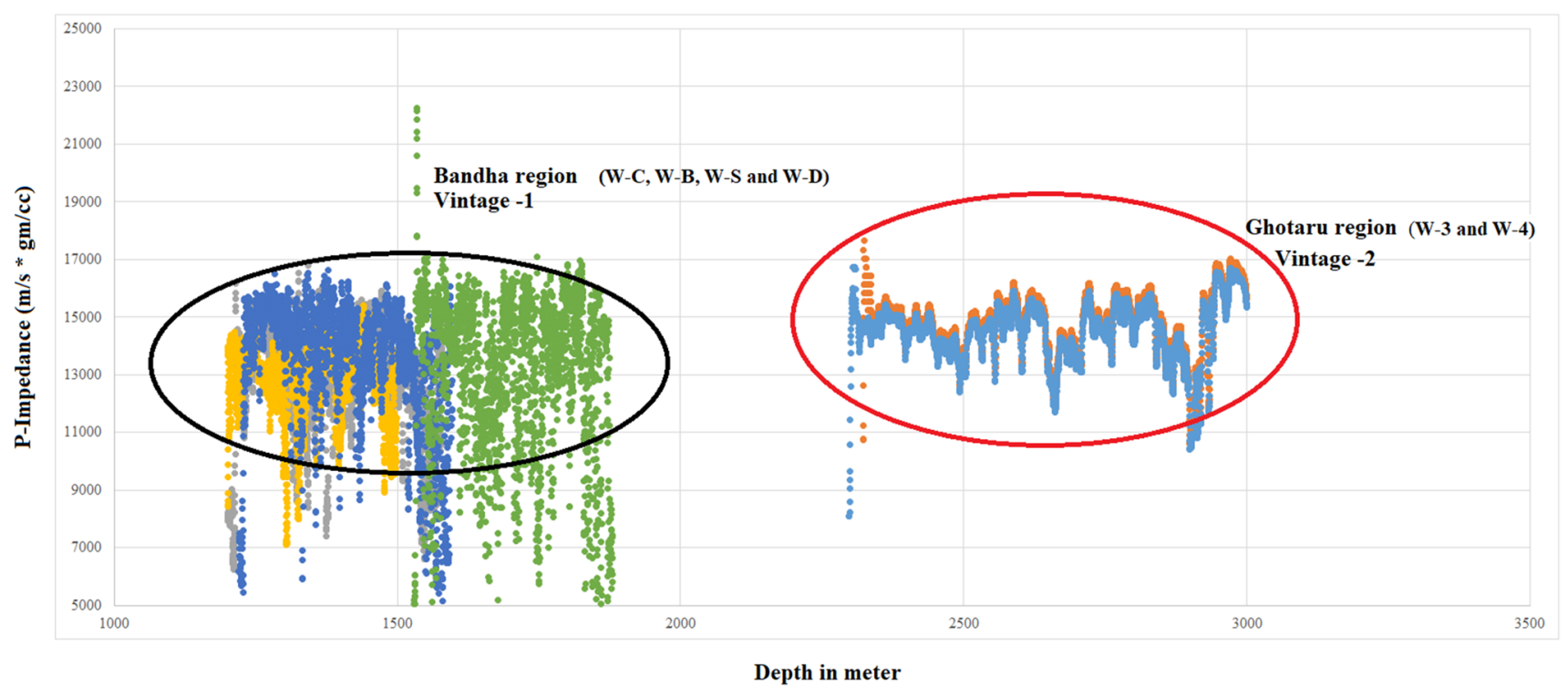

P-Impedance based on well data

(a)

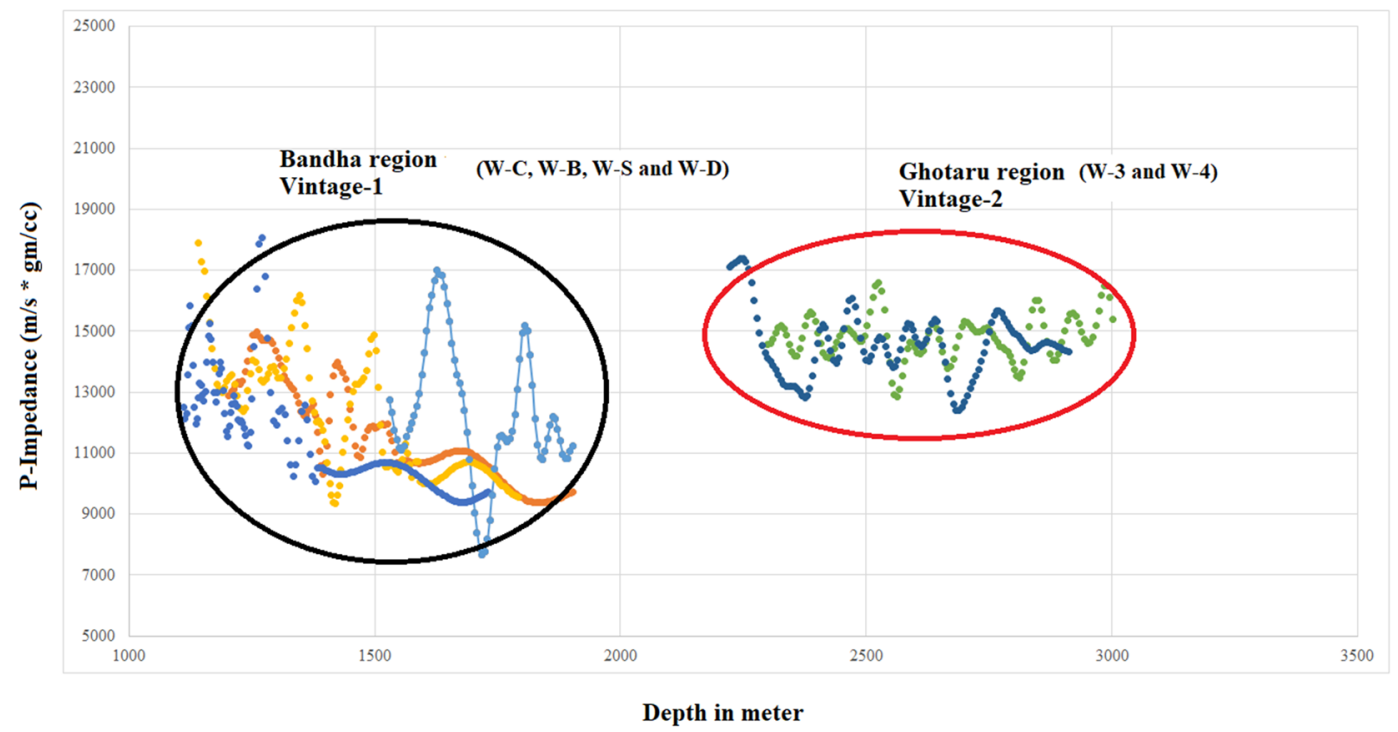

P-Impedance based on Post-stack seismic inversion

(b)

Fig. 22 Comparative analysis of the P-impedance log based on well data and Post-stack inverted data in depth scale; a distinct change of impedance values has been observed in both cases; a analysis has been carried out in the Bandha region; $\mathbf{b}$ analysis has been carried out in the Ghotaru region 


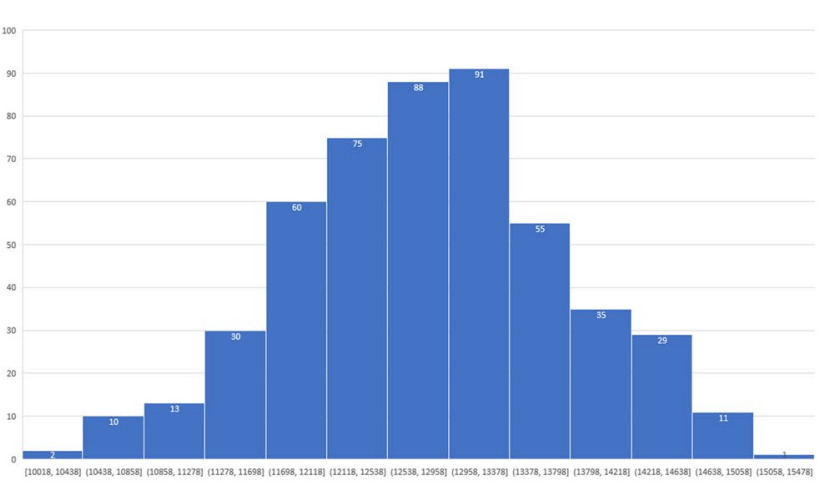

P10 Case

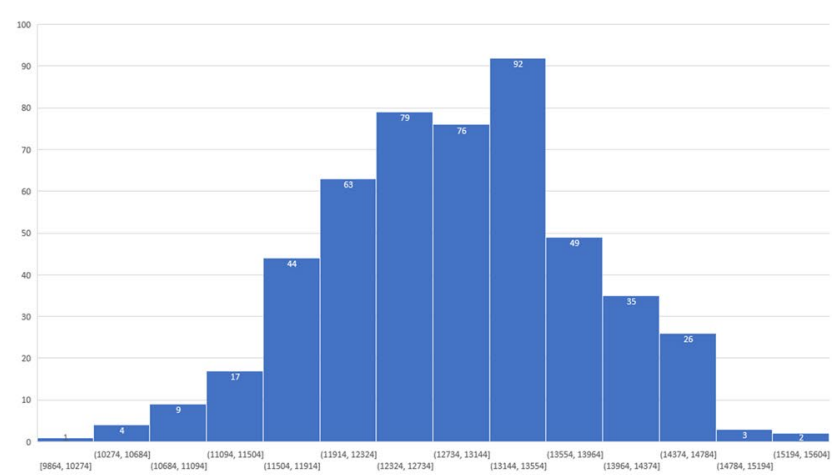

P50 Case

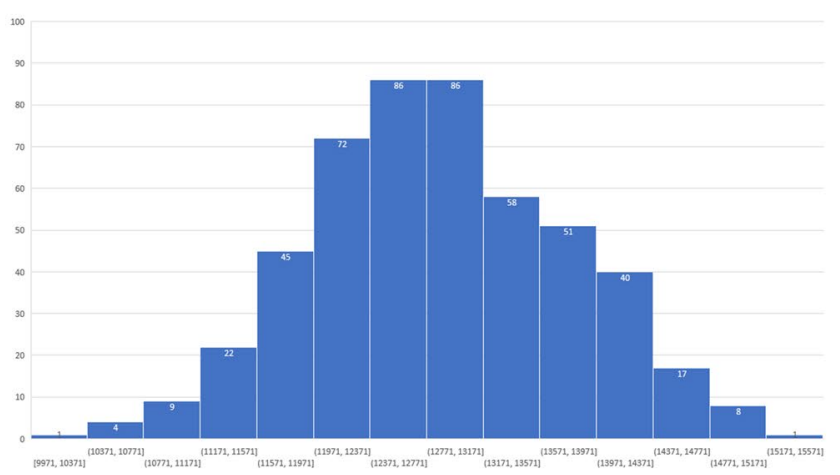

P90 Case

Fig. 23 Capture the Uncertainty of the estimated P-impedance volume from the post-stack inversion process based on P10, P50 and P10 analysis

the study area in the Ghotaru region. These encouraging results are very limited in the Bandha region. This difference of the results between the Ghotaru and Bandha region can be captured through proper analysis of the sediment property based on P-impedance. In this study, the focus was on the Jaisalmer Formation only. The outcome shows the different nature of the limestone facies due to overburden thickness and structural deformation, which leads to the development of high impedance limestone in the Ghotaru region (seismic survey vintage \# 2). In contrast, similar limestone is not available in the Bandha region (seismic survey vintage \# 1). The limestone unit in the Ghotaru region is highly deep-seated in comparison to the Bandha region. Low impedance limestone is discrete in nature, and everywhere potentiality is not similar. The current study shows the higher chances for the presence of hydrocarbon-bearing reservoir in the deeper section in the Jaisalmer Formation with comparatively high P-impedance limestone.

Acknowledgements Gracefully acknowledgement to the Gujarat State Petroleum Corporation Limited regarding the encouragement of research activity and various technical data support, analysis, and various application support for research activity. We gratefully acknowledge the National Data Repository (NDR), DGH (Director General of
Hydrocarbon) India regarding the encouragement of research activity and various technical data support, analysis, and application support for research activity. Our sincere gratitude to HLS ASIA and Schlumberger India to acquire the well $\log$ data in the study area and provide other technical support in the study area. The authors are profoundly thankful to the researchers of the Geophysical Data Quantitative Interpretation Lab. (GQIL), Department of Applied Geophysics, IIT(ISM) Dhanbad especially Sagnik Biswas for providing support to carry this research work. Our sincere thanks to all those associated team members and service providers who are directly or indirectly involved in the study area's technical work.

Authors' contributions SDG $60 \%$ contribution to the manuscript has been given by Saurabh, such as conceptualization, analysis of the result, drafting of the manuscript, figure and table preparation. SKS $30 \%$ contribution to the manuscript has been given by Sugata, such as conceptualization, project study, gap analysis, analysis of the result, uncertainty study, drafting of the manuscript, figure and table preparation. RC $10 \%$ contribution to the manuscript has been given by Raman, such as conceptualization, drafting of the manuscript, figure and table preparation.

Funding No funding is available. 


\section{Declarations}

Conflict of interest The authors declare that they have no known competing financial interests or personal relationships that could have appeared to influence the work reported in this paper.

\section{Ethics approval Yes.}

\section{Consent to participate Yes.}

\section{Consent for publication Yes.}

Open Access This article is licensed under a Creative Commons Attribution 4.0 International License, which permits use, sharing, adaptation, distribution and reproduction in any medium or format, as long as you give appropriate credit to the original author(s) and the source, provide a link to the Creative Commons licence, and indicate if changes were made. The images or other third party material in this article are included in the article's Creative Commons licence, unless indicated otherwise in a credit line to the material. If material is not included in the article's Creative Commons licence and your intended use is not permitted by statutory regulation or exceeds the permitted use, you will need to obtain permission directly from the copyright holder. To view a copy of this licence, visit http://creativecommons.org/licenses/by/4.0/.

\section{References}

Anitha G, Ramana MV, Ramprasad D, Anuradha M (2014) Shallow geological environment of Krishna-Godavari offshore, eastern continental margin of India as inferred from the interpretation of high resolution sparker data. J Earth Syst Sci 123:329-342

Arora K, Kilaru S, Dixit M, Sarkar D (2012) Jaisalmer basin of western Rajasthan: a gravity perspective, The 2nd South Asain geoscience conference and exhibition, GEO India 2011

Bastia R, Nayak P (2006) Tectonostratigraphy and depositional patterns in Krishna Offshore basin, Bay of Bengal. Leading Edge 25:839-845

Bateman RM (1985) Openhole log analysis and formation evaluation. Prentice Hall PTR, New Jersey, p 647

Berge TB, Aminzadeh F, Groot PD, Oldenziel T (2002) Seismic inversion successfully predicts reservoir, porosity, and gas content in Ibhubesi field, Orange Basin, South Africa. Leading Edge $21: 338-348$

Biswas SK (1987) Regional tectonic framework, structure and evolution of the western marginal basins of India. Tectonophysics 135(4):307-327

Castagna JP, Backus MM (1993) Offset dependent reflectivity-theory and practice of AVO analysis. Society of Exploration Geophysicists, Tusla

Cemen I, Fuchs J, Coffey B, Gertson R, Hager C (2013) Correlating porosity with acoustic impedance in sandstone gas reservoirs: examples from the Atokan sandstones of the Arkoma Basin, South Eastern Oklahoma. AAPG annual convention and exhibition

Chahal R, Gupta SD (2020) Capture the variation of the pore pressure with different geological age from seismic inversion study in the Jaisalmer sub-basin, India. Pet Sci 17:1556-1578

Chatterjee R, Datta Gupta S, Farooqui MY (2013) Reservoir identification using full stack seismic inversion technique: a case study from Cambay basin oilfields, India. J Pet Sci Eng 109:87-95

Chow JJ, Li MC, Fuh S (2005) Geophysical well log study on the paleo environment of the hydrocarbon producing zones in the Erchungchi Formation, Hsinyin, SW Taiwan. TAO, pp 16,531-16,543
Clavier C, Coates G, Dumanoir J (1984) Theoretical and experimental bases for the dual-water model for interpretation of shaly sands, Society of Petroleum Engineers of AIME, Society of Petroleum Engineers Journal 153-168

Dasgupta SK (1975) A revision of Mesozoic-Tertiary stratigraphy of the Jaisalmer Basin, Rajasthan. Indian J Earth Sci 2(1):77-94

Dasgupta SK (1974) The stratigraphy of the West Rajasthan Shelf. Proc. IV, Indian Colloq. Micropal. and Strati., 219-223

Desai and Saklani (2014) Ichnofabric analysis of the Tithonian shallow marine sediments (Bhadasar Formation) Jaisalmer Basin, India. J Earth Syst Sci 123(6):1413-1431

Faust LY (1953) A velocity function including lithologic variations. Geophysics 18:271-288

Gardner GHF, Gardner LW, Gregory AR (1974) Formation velocity and density - the diagnostic basics for stratigraphic traps. Geophysics 39:770-780

Gupta R, Bartaria S, Shukla RK (1996) Source Rock evaluation of Jaisalmer Basin, ONGC rep. KDMIPE (unpublished/open access)

Henderson AL, Najman Y, Parrish R, BouDagher-Fadel M, Barford D, Garzanti E, Ando S (2010) Geology of the Cenozoic Indus Basin sedimentary rocks: paleoenvironmental interpretation of sedimentation from the western Himalaya during the early phases of IndiaEurasia collision. Am Geophys Union, Tectonics, v. 29(6):1-35

Report from Director General of Hydrocarbon (DGH) (2007) http:// www.dghindia.org

Inam A, Clift PD, Giosan L, Tabrez AR, Tahir M, Rabbani MM, Danish M (2007) The geographic, geological and oceanographic setting of the Indus River, Large Rivers: geomorphology and management. John Wiley \& Sons, Ltd, pp 333-346

Jain S, Garg R (2012) Biostratigraphic implications of the record of genus himalayites from the late Tithonian sediments of Jaisalmer, western India. J Palaeontol Soc India 57(2):105-111

Krishna J (1987) An overview of the Mesozoic Stratigraphy of Kachch and Jaisalmer Basin. J Paleontol Soc India 32:136-149

Mangasi M, Haris A (2018) Application of seismic post-stack inversion for gas reservoir delineation: a case study of Talang Akar Formation, South Sumatera Basin, AIP conference proceedings, 2023, 020269

Maurya SP, Sarkar P (2016) Comparison of post stack seismic inversion methods: a case study from Blackfoot Field, Canada. Int J Sci Eng Res 7(8):1091-1101

Mishra PC, Sharma PC (1986) Geological analysis of Lower GoruFormation with special reference to hydrocarbon occurrence, Jaisalmer basin, Rajasthan. ONGC report (unpublished/open access)

Mitra P, Mukherjee MK, Mathur BK, Bhandari SK, Qureshi SK, Bahukhandi GC (1993) Exploration and hydrocarbon prospect in Jaisalmer Basin, Rajasthan. In: Biswas SK (ed) Proc. Second seminar on Proliferous Basins, India, 2, 235-284

Pandey R, Maurya AS (2020) Hydrocarbon uncertainty based on facies analysis: middle jurassic sequence (Jaisalmer Formation), Jaisalmer Basin, Rajasthan. J Geol Soc India 95:301-307

Pandey DK, Choudhary S, Bahadur T, Swami N, Poonia D, Sha J (2012) A review of the Lower-lowermost Upper Jurassic facies and stratigraphy of the Jaisalmer Basin, western Rajasthan, India. VoluminaJurassica 10:61-82

Pandey R, Kumar D, Maurya AS, Pandey P (2019) Hydrocarbon generation potential of source rocks in Jaisalmer Basin, Rajasthan, India. Curr Sci 116(5):822-827

Pradhan N, Datta Gupta S, Mohanty PR (2019) Velocity anisotropy analysis for shale lithology of the complex geological section in Jaisalmer sub-basin, India. J Earth Syst Sci 128:209

Singh NP (2006) Mesozoic Lithostratigraphy of the Jaisalmer Basin, Rajasthan. J Palaeontol Soc India 51(2):1-25

Singh NP, Sharma M, Jha N, Tewari R, Saleem M, Matsumaru K, Ehiro M, Kojima S, Jauhri AK, Misra PK (2006) Mesozoic 
Lithostratigraphy of the Jaisalmer Basin, Rajasthan. J Palaeontol Soc India 51:1-25

Srivastava S, Pandey VJ, Sharma DC, Singh NP (1995) Paleo environmental reconstruction for subsurface sedimentary sequence around Shahgarh sub-basin, Western Rajasthan, India. Proc. Petrotech, pp 149-160

Srivastave N, Ranawat ST (2015) An overview of Yellow Limestone deposits of the Jaisalmer Basin, Rajasthan, India. Vol Jurass XIII(1):107-112

Taner MT (2001) Seismic attributes. CSEG Recorder, September, $48-56$

Upadhyay H (1991) Depositional environment and reservoir characterisaticof Jaisalmer Formation, Jaisalmer Basin, Rajasthan. In: Pandey J, Banerjee V (eds) Proc. Conf. Integ. Expl. Res.-Achiev. \& Pers., pp 349-355

Wandrey CJ, Law BE, Shah HA (2004) Sembar Goru/Ghaij total petroleum system Indus Sulaiman-Kirthar geologic province, Pakistan and India, USGC, 2208C, 1-23
Weber KJ (1987) Hydrocarbon distribution patterns in Nigerian growth fault structures controlled by structural style and stratigraphy. J Pet Sci Eng 1:91-104

Yalamanchi P, Datta Gupta S (2021) Selection of a suitable rock mixing method for computing Gardner's constant through a Machine Learning (ML) approach to estimate the compressional velocity: a study from the Jaisalmer sub-basin, India. Pure Appl Geophys. https://doi.org/10.1007/s00024-021-02733-y

Publisher's Note Springer Nature remains neutral with regard to jurisdictional claims in published maps and institutional affiliations 